\title{
A comparison of the Beveridge curve dynamics in Italy and USA
}

\author{
Carlo Di Giorgio · Massimo Giannini
}

Received: 28 August 2008 / Accepted: 12 July 2011

C Springer-Verlag 2011

\begin{abstract}
In this article, we investigate the Beveridge curve dynamics in the USA and Italy by means of a cointegrated structural VAR model. A simple economic model is introduced to motivate the identifying assumptions of the empirical analysis. A stable long-run relationship is found for both countries. In order to study the dynamic behaviour of the model, and to decompose unemployment and vacancy fluctuations, we identify three common stochastic trends. The empirical results suggest that there are some sources of hysteresis in unemployment in both countries. Transitory shocks are also identified to account for the short-run dynamics of the model. The approach allows us to detach the long-run from the short-run dynamics, in order to provide information on the cyclical and structural Beveridge curve.
\end{abstract}

Keywords Beveridge curve $\cdot$ Common trends $\cdot$ SVECM $\cdot$ Hysteresis

JEL Classification $\quad$ C32 $\cdot$ E24 $\cdot$ J63

\section{Introduction}

The Beveridge curve that identifies the negative relationship between unemployment rate and job vacancies, is still often used to identify the state of the labour market. Although the Beveridge curve is not a structural economic relationship, in the sense that workers and firms do not consciously decide to make unemployment negatively related to vacancies, in this article, through some methodological and empirical steps,

C. Di Giorgio $(\bowtie) \cdot$ M. Giannini

University of Rome "Tor Vergata", Via O. Raimondo 18, 00173 Rome, Italy

e-mail: carlo.digiorgio@uniroma2.it

M. Giannini

e-mail: massimo.giannini@uniroma2.it

Published online: 13 September 2011 
we try to explain the underlying behaviours of the workers and firms, in accumulating skills, setting wages and the involved policy-makers' actions, which indirectly result in the patterns of the Beveridge curves of various countries. In order to study the dynamic behaviour of the Beveridge curve in two countries, we identify a commontrends model that allows us to decompose unemployment and vacancy fluctuations stemming from three permanent shocks, namely a technology shock, a labour supply shock and a reallocation shock for both countries. Our aim is to isolate shocks and structural changes from the Beveridge curve, to assess its long-run dynamics and adjustment. The rationale is in the inner functioning of the Beveridge curve itself. As is well known, the latter is a macro-long-run relationship stemming from a job-search activity in the labour market; it sums up the behaviour of two elementary units of the economy: firm and worker. What we observe in the job market data is the consequence of such elementary processes. At an aggregate analysis, the Beveridge curve shows fuzzy movements, alternating relative stable patterns to large changes in position and slope, as well as non-monotone transitional paths (see Blanchard and Diamond 1989; Bleakley and Fuhrer 1997). In other words, data show that there is a remarkable level of churning in the labour market; movements of the Beveridge curve are the economywide response to a complex microeconomic framework. The matching function is the common thread between these two worlds. This leads once more to the importance of separating long-run from short-run movements of the Beverdige curve. However, in doing so, we have to bear in mind that job search is affected by a large number of variables, spanning from individual, like skills and education, to institutional, like labour market tightness and rigidity. For such a reason, we cannot expect, that, a priori, that the Beverdige curve dynamics follows similar movement in different countries, especially when the latter differ remarkably in the institutional setting. After significant labour market reforms in the 1990s and the early 2000s, labour market outcomes have improved in Italy, implying an increase in employment and labour force participation, jointly to a substantial reduction in the unemployment rate (dropping to around $6 \%$ in 2007). However, this is not enough; employment rates in Italy continue to be substantially lower than those in most other European countries. Moreover, the labour market is characterized by large inequities induced by liberalization reforms. Main reforms were the 1997 Treu (former labour ministry) and 2003 Biagi (The Chief Advisor, Labour Ministry); they introduced substantial 'flexibility' to the Italian labour market thanks to atypical jobs. But this has induced an increasing dualism of the labour market. In fact, 'most of the employment gains since 1995 were in temporary and part-time employment. Between 1995 and 2007, the share of temporary employment increased from 7.2 to $12.4 \%$, and the share of part-time employment from 10.5 to over $15 \%$. In absolute terms, the number of workers in temporary work arrangements more than doubled during that time, while permanent employment increased by only 7 percent' (Schindler 2009). Such a fact, jointly with still too-tight a national wage bargaining system, does not allow Italy a real take-off in the labour market. Moreover, product market still needs to be regulated, and additional reforms are needed. In the US labour, market is much more free, jointly with an economic setting working in a more competitive way than in Italy. Wage bargaining is limited and so is fiscal pressure. This makes Italian and than US labour market barely comparable, and for such a reason, we are going to investigate the dynamics of Beveridge curve in both the countries. 
Under this point of view, Italian and the US labour markets are often invoked as two polar cases, because of different wage rigidities and search mechanisms. As pointed out in Flinn (2002, p. 613):

We have chosen Italy and the US to make our substantive points because the labour market institutions in these two countries are well-known to be quite dissimilar.

In particular, Flinn focuses on the role of institutional restrictions on layoffs and dismissals in accounting for the lower level of cyclical variability in employment levels observed. Markets with rigid labour regulations and centralized wage setting are often thought to be inefficient but egalitarian. This has remarkable effects on the Beveridge curve dynamics over time; we should expect a more sluggish dynamics in countries, characterized by wage rigidity and inefficient job search, like Italy, and conversely in countries, where labour market is more flexible and reactive to shocks, like US.

To achieve the goal, in the first stage, we present a simple labour market model and its solution, in a way to investigate upon the model cointegration properties and to assess the structural stability of the equilibrium relationship. The estimated models allow us to identify — for both the countries—different stages representing low- and high-efficiency phases of the labour market. Out of equilibrium, dynamics has been investigated by the common stochastic trends approach; this allows us to study the economic model in its long- and short-run dynamics.

This study is close in spirit to Blanchard and Diamond (1989) (henceforth BD); in that article, the authors try to isolate short-run dynamics from the steady state to assess whether the US Beveridge curve undertakes regular movements in the $u$ (unemployment)and $v$ (vacancy) space, even though, unlike those authors, we use a discrete time model of the labour market. Theoretical microfoundation of the short-run dynamics in the Beverdige curve is investigated in Giannini (2006), by means of the Dynamic Monte Carlo Markov Chain approach.

Sections 2 and 3 of the article describe the data and present a small model of the labour market that will be used to motivate the identifying restrictions in the following empirical analysis. Section 4 contains the cointegration properties of the model for the US. In Sect. 5, we identify and estimate a common trends model and use it to study the dynamics of the US Beveridge curve. Section 6 describes the empirical results for Italy. Section 7 concludes and tries to describe a final comparison of the results of the analysis in the two countries.

\section{The data}

We use quarterly data for the US and Italy extended to cover the period 1960:1-2007:4 for US, 1980:1-2006:4 for Italy: details are in the Appendix B. The variables are the $\log$ of the civilian labour force, the log of the productivity measured as real output per worker, the unemployment rate and the vacancy rate, $x_{t}=\left[l_{t}, y_{t}-e_{t}, l_{t}-e_{t}, v_{t}\right]^{\prime}{ }^{1}$

\footnotetext{
${ }^{1}$ Unemployment rate can be defined as $u_{t} \approx l_{t}-e_{t}$, where $l_{t}$ and $e_{t}$ are the natural logarithms of labour force and employment, respectively.
} 


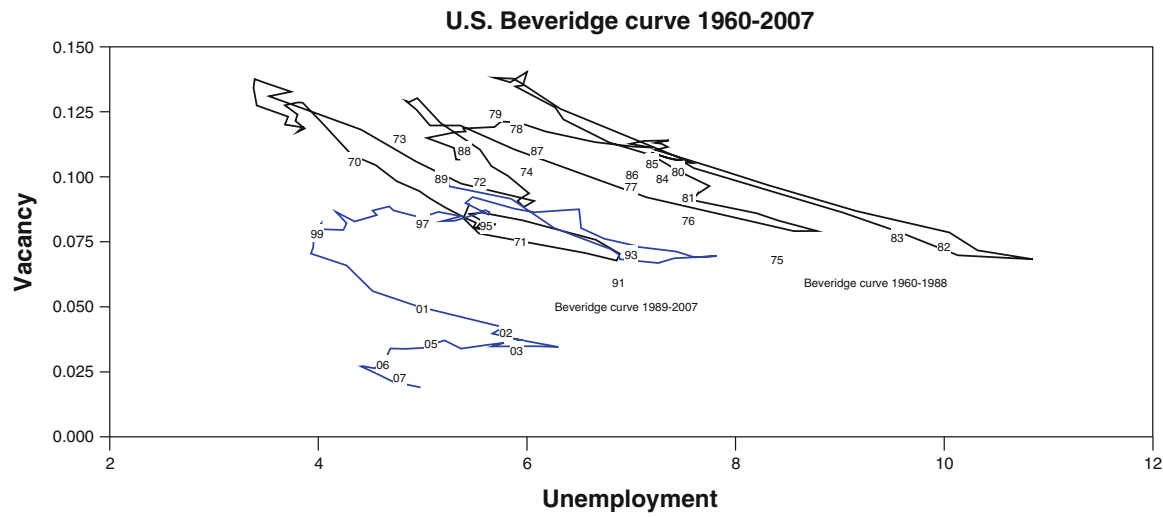

Fig. 1 US Beveridge curve

The variables for the US are graphed in Fig. 15 in Appendix. The first and the third panels show the strong trend in both the labour force and productivity. The second and the fourth panels graph the unemployment and the vacancy rates with less marked trends. Looking at the chart of vacancy data, the remarkable downward trend characterizing the data since the early 1990s is likely to have been helped by the recent increase in alternative sources of job search, such as the Internet, which have reduced the importance of the traditional help-wanted advertisements.

In the first step of the analysis, we investigate upon the statistical properties of the series; if the series are non-stationary, then will be evaluated the presence of cointegration. ADF and KPSS unit root tests carried out on the levels of the single variables suggest that all the variables can be regarded as non-stationary for both the countries. In empirical investigation on these type of data, Juselius (2006), suggests of testing stationarity using the cointegrated VAR approach rather than the single equation unit root tests; however, results reported in Appendix Tables A1 and reftabA2, confirm our single variable unit root testing. ${ }^{2}$

In Fig. 1, the US Beveridge curve is graphed for the full sample; it is worth noting the inward shift of the curve from the late 1980s to the early 2000s. As pointed out in Pissarides (2000), this process can be described defining the job-matching function

$$
h_{t}=\alpha \cdot m\left(u_{t}, v_{t}\right), \quad \frac{\partial m}{\partial u}>0, \frac{\partial m}{\partial v}>0
$$

where the rate of job matching or hiring, $h$, is expressed as a function of the unemployment rate, $u$, and the job vacancy rate, $v$, while $\alpha$ is a parameter that describes the efficiency of the matching process. It is usually assumed that the matching function is characterized by constant returns to scale, and it is increasing in both arguments. These assumptions imply that the Beveridge curve is convex to the origin and downward sloping in $u-v$ space. It represents a steady-state relationship in the sense that

\footnotetext{
2 Unlike the usual univariate unit root tests that have non-stationarity as the null, this multivariate procedure has stationarity as the null hypothesis, given the cointegration space.
} 
the job matching rate, $h$, i.e. the percentage of workers flowing out of unemployment into jobs is equal to the flow into unemployment, at an exogenous constant rate of job separation, $s$. Outward or inward shifts of the curve over time are due to lower or higher levels of the efficiency of the job matching (measured by $\alpha$ ); these movements are induced by changes in the search intensity of firms and workers, changing demographics, barriers to occupational and geographical mobilities, etc.

In order to identify short- and long-run dynamics of the Beveridge curve, we perform firstly the cointegration analysis, applying Johansen's procedure, while in the second stage, we use, if any, the cointegration properties of the VECM to derive and identify the common stochastic trends that drive the system. We study the characteristics of the system found in the first stage carrying out a common trends analysis to analyse the properties of the Beveridge curve.

\section{A model of the labour market}

The model used in this article consists of a production function, a labour supply relation a Beveridge curve relation, and a labour market-tightness equation:

$$
y_{t}=\beta e_{t}+\theta_{t}
$$

where $y_{t}$ is the output, $e_{t}$ is the employment, and the parameter $\beta$ measures returns to scale. $\theta_{t}$ is a stochastic technology trend and evolves according to

$$
\theta_{t}=\theta_{t-1}+\varepsilon_{y, t}
$$

with the pure technology shock $\varepsilon_{y, t}$. In Appendix $\mathrm{C}$ is reported the production process with two inputs, labour and capital, and the reasons why, assuming the capital-labour ratio to be stationary, $\theta_{t}$ can be considered as a technology shock. ${ }^{3}$

$$
l_{t}=\delta y_{t}+\psi_{t}
$$

According to Eq. 2 labour force is influenced by the output, since positive aggregate demand movements lead to a decrease in unemployment, as well as an increase in the labour force, and a stochastic labour supply trend according to the following process:

$$
\psi_{t}=\psi_{t-1}+\varepsilon_{s, t}
$$

where $\varepsilon_{s, t}$ is a pure labour supply shock.

Equation 3 is a Beveridge curve relation,

$$
u_{t}=-\eta v_{t}+\omega_{t}
$$

\footnotetext{
3 Note that this simplification could cause problems if we were analysing the goods market, but is pretty harmless if only the labour market is considered.
} 
where $\omega_{t}$ is an exogenous reallocation variable. The relationship is consistent, at aggregate level, with changes in shocks which conduce, at least in the short run, at a strong negative correlation between unemployment and vacancies. Reallocation trend evolves according to

$$
\omega_{t}=\omega_{t-1}+\varepsilon_{c, t}
$$

with the pure reallocation shock $\varepsilon_{c, t}$.

$$
v_{t}-u_{t}=\gamma\left(y_{t}-e_{t}\right)+\varepsilon_{m, t}
$$

In Eq. 4 labour market tightness ( $v-u$ ratio) — that is a broad measure of the cycle-is influenced by the labour productivity: for a given separation rate $s$, an increase in labour productivity reduces the unemployment rate and increases the vacancy rate, increasing the $v-u$ ratio, so that unemployment and vacancy move in opposite direction. The $v-u$ reflects the intensity of search activities in the matching market, and therefore through it, favours employment movements, i.e. the, high values of the ratio indicate that jobs are relatively abundant and imply an efficient labour market. $\varepsilon_{m, t}$, is a pure market tightness shock, and if Eq. 4 is a stationary relation, then $\varepsilon_{m, t}$ obeys the following process:

$$
\varepsilon_{m, t}=\phi \varepsilon_{m, t-1}+\varphi_{m, t},|\phi|<1
$$

In the equilibrium relationship (4), positive changes in labour productivity, among others, decrease marginal costs of firms, and the additional demand caused by lower prices match the increase in labour demand, so that vacancies increase and unemployment decreases; hence, vacancy-unemployment ratio increases showing that it is pro-cyclical. The increase in job creation lowering unemployment improves workers' wage-bargaining position, and therefore puts upward pressure on wages absorbing over a period the productivity increase pushing the variables towards the equilibrium. ${ }^{4}$ All the variables are expressed in natural logarithms, and the initial values of the stochastic shocks $\left(\theta_{0}, \psi_{0}, \omega_{0}\right)$, which for simplicity are assumed equal to zero.

It is convenient to rewrite and solve the model in Eqs. 1-4 in terms of the main variables of the study: labour force $l_{t}$, labour productivity $\left(y_{t}-e_{t}\right)$, unemployment $u_{t}$, and vacancy $v_{t}$. By doing so, we obtain

$$
\left(\begin{array}{cccc}
1-\delta & -\delta & \delta & 0 \\
1-\beta & 1 & \beta-1 & 0 \\
0 & 0 & 1 & \eta \\
0 & -\gamma & -1 & 1
\end{array}\right)\left(\begin{array}{c}
l_{t} \\
y_{t}-e_{t} \\
l_{t}-e_{t} \\
v_{t}
\end{array}\right)=\left(\begin{array}{c}
\psi_{t} \\
\theta_{t} \\
\omega_{t} \\
\varepsilon_{m, t}
\end{array}\right)
$$

or in compact form

\footnotetext{
4 As argued by Shimer (2005), if wages are determined according to a Nash bargaining process, large labour productivity shocks may have little effect on the $v-u$ ratio. Alternative wage determination mechanisms generating more rigid wages can amplify the effects of productivity shocks, with unemployment that can show a high degree of persistence.
} 


$$
\boldsymbol{B} \boldsymbol{x}_{t}=\boldsymbol{\Phi}_{t}, \quad \boldsymbol{\Phi}_{t}=\psi_{t}, \theta_{t}, \omega_{t}, \varepsilon_{m, t}
$$

From the solution of the system (5), we obtain

$$
\left[\begin{array}{c}
l_{t} \\
y_{t}-e_{t} \\
l_{t}-e_{t} \\
v_{t}
\end{array}\right]=\Gamma\left[\begin{array}{cccc}
\eta(1-\beta \gamma+\gamma)+1-\delta(1+\eta+\eta \gamma) & -\beta \delta & -\beta \eta \delta \\
(1-\beta)(1+\eta) & (1-\delta)(1+\eta) & 1-\beta & \eta(1-\beta) \\
\eta \gamma(1-\beta) & \eta \gamma(1-\delta) & 1-\beta \delta & \eta(1-\beta \delta) \\
\gamma(1-\beta) & \gamma(1-\delta) & 1+\gamma(1-\beta)-\beta \delta & 1-\beta \delta
\end{array}\right]\left[\begin{array}{c}
\psi_{t} \\
\theta_{t} \\
\omega_{t} \\
\varepsilon_{m, t}
\end{array}\right]
$$

where $\Gamma$ is given by

$$
\Gamma=\frac{1}{\eta(1-\beta \gamma+\gamma)-\beta \delta(1-\eta)+1}
$$

From Eq. 6, it can be seen that the four variables are driven by four unobserved components: the three common trends in labour supply: $\left(\psi_{t}\right)$, technology $\left(\theta_{t}\right)$, reallocation $\left(\omega_{t}\right)$; and a stationary component due to market-tightness shocks $\left(\varepsilon_{m, t}\right)$. The model suggests that stochastic shocks in labour supply, technology, and reallocation may cause hysteresis phenomena in unemployment. Although the mechanisms which generate hysteresis in the model are quite simple, the methodology, modelling even other variables like wages, inflation, employment, capacity utilization (or output gap), may be useful to study more elaborate theories about unemployment persistence, for example, the theories of the unemployment range of equilibria (McDonald 1990), the pure hysteresis model of the capital scrapping (Carlin and Soskice 1990), which derive from demand management policies, or, e.g. as it is used in the hysteresis common trends model of Jacobson et al. (1997). The range of equilibria is a range of rates of unemployment within which the rate of unemployment is exerting no disequilibrium pressure on the rate of inflation, and so by integrating the labour market common trends model with a two- regime Markov switching model, it may be possible to study the unemployment-inflation dynamics related with an unemployment range of equilibria and if equilibrium unemployment may follow a hysteresial process. On the other hand, if we consider the model with a demand variable (e.g. public expenditure), then it is possible to analyse long-run effects on unemployment that can be explained by hysteresis phenomena of aggregate demand shocks, like, for example, the capital scrapping model of Carlin and Soskice (1990). Our common- trends model only tries to explain that there are some shocks which have permanent effects on unemployment and vacancy, and others which have only temporary effects, and to examine the sources of these shocks in more detail. 


\section{The cointegrating properties of the $V E C M$ for US}

Johansen's cointegration analysis is applied to the following linear VECM with four variables $^{5}$ and six lags 6

$$
\Delta x_{t}=\alpha \beta^{\prime} x_{t-1}+\sum_{i=1}^{p} \Gamma_{i} \Delta x_{t-i} \Psi D_{t}+\varepsilon_{t}, \quad \varepsilon_{t} \sim \text { i.i.d. } \quad N_{n}(0, \Omega)
$$

where $\boldsymbol{x}_{\boldsymbol{t}}$ is a $n \times 1$ vector of endogenous variables, $\boldsymbol{D}_{\boldsymbol{t}}$ is a vector of general deterministic terms and $\varepsilon_{t}$ is an error term assumed to be i.i.d. multivariate normally distributed with constant variance. Choice of lag length, misspecification analysis and rank determination are conducted using the standard tools suggested by Juselius (2006). The results of the cointegration tests are shown in Appendix Table A3 with the trace statistics, the Bartlett corrections of the rank test statistic, ${ }^{7}$ the tabulated critical values and $P$-values. ${ }^{8}$ Using a sequential procedure, when the Bartlett correction factor of the rank test statistic is used, the null of non-cointegration can be rejected in favour of the alternative of the existence of one of the cointegration vectors among the four variables, i.e. $r=1 .{ }^{9}$ Using dummy variables in the model can affect the distribution of the trace test. For such non-standard models, a simulation of the asymptotic critical values has been carried out applying the methodology proposed by Johansen and Nielsen (1993), ${ }^{10}$ and we noted that their difference does not lead us to reconsider the choice of cointegration rank.

With four variables and one cointegration relationship, Stock and Watson (1988) show that there is a simple duality between the concepts of cointegration and common trends, and so when we have an $n$-dimensional vector of variables, with $r$-dimensional cointegration vectors, there are $k=n-r$ common stochastic trends that drive the system of the variables (i.e. $k=3$ ).

\footnotetext{
5 Labour force $\left(l_{t}\right)$ and labour productivity $\left(y_{t}-e_{t}\right)$ are in natural logarithms. Unemployment and vacancy rates were transformed in: $\mathrm{ur}_{t}=\log \left(1+\mathrm{UR}_{t} / 100\right)$ and $\mathrm{vr}_{t}=\log \left(1+\mathrm{VR}_{t} / 100\right)$, so that the $\log$ transformation aids normality in residuals, and when $x$ is small, $\log (1+x) \approx x$ by Taylor expansion.

${ }^{6}$ Hannan-Quinn and Schwarz information criteria led to the choice of a VAR(4); we found that residuals improved their statistical properties with six lags, confirming that the residuals are not serially correlated in all the equations, while the Bera and Jarque tests do not allow for rejection of the normality.

7 Johansen (2002) suggests to apply this correction factor that improves the finite sample properties and corrects for the under-rejection of the trace test statistic in small samples.

8 The results were obtained using CATS in RATS, version 2.

${ }^{9}$ Four impulse dummy variables are included in the model to improve the statistical properties of the residuals justified on economic grounds, and to account for the oil shocks. Following Hansen and Johansen (1999), when a recursive trace test is carried out, we cannot reject the hypothesis of one cointegrating relationship (Appendix Fig. 16).

${ }^{10}$ See Appendix D and Table A4.
} 
Overidentifying restrictions on the cointegrating vector were applied and accepted by LR test: ${ }^{11}$ the estimated cointegrating relationship can be written as

$$
v_{t}-u_{t}=1.78\left(y_{t}-e_{t}\right)
$$

The stationary relationship shows that the elasticity of $v-u$ ratio with respect to labour productivity is estimated as $\hat{\gamma}=1.78,{ }^{12}$ implying that labour productivity shocks are consistent with a downward sloping Beveridge curve. In particular, increases in labour productivity lead to high vacancies, since firms have incentive to open more vacancies, and low unemployment that characterize a tight labour market, since unemployed workers find jobs more quickly, so that the process can be observed by fluctuations in derived demand for labour, as reflected in vacancy movements, i.e. shifts in labour demand are caused by changes in productivity, which suggest to be an important driving force of the cyclical unemployment dynamics, rather than labour supply shocks that, how it is shown in the following analysis, are more important in the long run. In this view, as suggested by Shimer (2005), an increase in labour productivity relative to the recruitment cost to advertise a job vacancy, makes unemployment relatively expensive and vacancies relatively cheap, so that the market pushes towards vacancy substitutions, and the increased job creation decreases the unemployment rate, moving the economy along a downward sloping Beveridge curve. Fujita and Ramey (2007), in a quasi-VAR system of the US labour market, report the IRF of the $v-u$ ratio to a one standard deviation productivity shock, showing, that as a result of the shock, that the labour market tightness rises rapidly for four quarters, then it reaches its steady state after about 15 quarters, showing some degree of sluggishness.

It is known that cointegration relationships can be interpreted as the forces that pull the variables towards an equilibrium after a shock has occurred, but some shocks can have permanent impacts on the variables. In this view, the non-stationarity of the observable unemployment rate (as well as vacancy rate) cannot be simply explained by nominal or real inertia that causes a sluggish adjustment towards a stationary equilibrium rate of unemployment. Indeed, when there are shocks that affect permanently the equilibrium path, i.e. policies oriented to change the unemployment rate (or inflation rate), they may cause shifts of NAIRU through movements of actual unemployment rate, introducing non-stationarity in the system. ${ }^{13}$

Before proceeding to the identification of which shocks could have permanent or transitory effects on unemployment and vacancy, to verify the constancy of the beta vector, following Hansen and Johansen (1999), we carry out a recursive estimation.

\footnotetext{
${ }^{11}$ Following Johansen (2000), using the Bartlett correction for tests on cointegrating relations in the VAR model, to give a better approximation to the finite sample distribution, LR test is $\chi^{2}(3)=7.2, P$-value* [0.065], Correction Factor: 1.53.

12 This result is consistent with (Shimer 2005) that computes (in a calibrated labour market model) an elasticity of the $v-u$ ratio with respect to labour productivity of 1.71 .

13 In the literature usually are exposed non-stationarity phenomena connected with the unemployment rate, rather than vacancies, since generally unemployment (or inflation) is considered an economic policy objective. Obviously, in the model, given the vacancy non-stationarity, shocks to the common-trend innovations can affect vacancies permanently.
} 
Based on recursive tests, max test shows the stability of the cointegration vector, with evident differences in the late 1970s and mid-1980s (Appendix Fig. 17). The recursive procedure, moreover, allows us an alternative way for investigating the beta vectors constancy, by testing whether some fixed value of beta, $\beta_{0}$, is contained in the space spanned by $\beta^{\left(t_{1}\right)}$ (test of 'Known Beta'). In other words, the test is based on the null hypothesis that the beta relations are constant over a reference period. It is displayed in Appendix Fig. 18. It can be noted that model constancy is accepted based on the $\boldsymbol{R}$-form model (concentrated model version), ${ }^{14}$ when the short-run effects had been corrected for, whereas it is rejected based on $\boldsymbol{X}$-form that is the equilibrium error as a function of short-run dynamics and deterministic components (full model) —in the 1970s and the early 1980s. This period is comprised between the oil shocks and comprises a fairly volatile sub period in the sample. With this test, the model suffers from non-constant parameters in the short-run structure, whereas in the long run, the full sample $\hat{\beta}$ would essentially be accepted, since the $\boldsymbol{X}$-form test is more likely to be influenced by the instability in the short-run coefficients. As pointed out by Juselius (2006), there is no waterproof rule to warrant whether the deviation from constancy requires a re-specification of the model, so she suggests that 'One useful way to thinking of the recursive tests is that they can provide a general assessment of the confidence we place on the conclusions from the model' (p. 150). In our conclusion, although $\boldsymbol{X}$-form of the US test of 'known beta' displays volatility at the beginning of the recursive sample, the model suffers from non-constant parameters in the short-run structure; when the latter are concentrated out, the model in the long run shows a reasonable amount of parameter constancy (the full sample $\hat{\beta}$ would essentially be accepted when the short-run effects are corrected for). Since the $\boldsymbol{X}$-form test is more likely to be influenced by the instability in the short-run coefficients, we do not think that this deviation from constancy requires a re-specification of the model, given also the other recursive tests (max test of $\boldsymbol{\beta}$-constancy, Eigenvalue time path graph: Appendix Figs. 17, 19) and the graph of the cointegration relationship (Appendix Fig. 20) that looks quite stable. Moreover, as suggested by Juselius (2006, chap. 7), the $\boldsymbol{R}$-form model, the 'clean' equilibrium adjustment form, is a more interpretable economic form. ${ }^{15}$ In order to analyse the long- and short-run dynamics and shifts of the Beveridge curve, we provide to carry out a common-trend analysis for the identification and the interpretation of the structural shocks of the model.

\section{Identification of permanent and transitory shocks}

The econometric methodology for the identification of the shocks that hit our SVECM relies on the common-trend analysis developed by King et al. (1991) and Warne (1993). The approach uses the cointegration properties of the data to identify the model using both short- and long-run restrictions. The analysis distinguishes between structural shocks with permanent effects on the level of the variables and transitory shocks with

\footnotetext{
14 See Appendix D for details on $\boldsymbol{R}$-form and $\boldsymbol{X}$-form models.

15 In the test of known beta, when the short- run fluctuations are concentrated out, the model shows a reasonable amount of parameter constancy.
} 
effects in the short run only. The permanent shocks are the sources of the common stochastic trends, at least to some of the series. As we said, the number of these shocks is $k=n-r$, and the number of transitory innovations is equal at the number of cointegrating relationships. From a common-trend model, it is known that temporary shocks to the stochastic trends have permanent effects, while short-run fluctuations are driven both by trend shocks and purely transitory shocks. In this sense, the structural and cyclical components of unemployment or vacancy are correlated, but still distinguishable. In order to identify the permanent and transitory shocks of our SVECM model, we use the cointegration properties found in the first stage of the analysis. Our structural common trends model is given by

$$
x_{t}=x_{0}+A \tau_{t}+\sum_{i=0}^{\infty} \Phi_{i} v_{t-i} ; \quad \tau_{t}=\left(\begin{array}{c}
\psi_{t} \\
\theta_{t} \\
\omega_{t}
\end{array}\right) ; v_{t}=\left(\begin{array}{c}
\varepsilon_{s, t} \\
\varepsilon_{y, t} \\
\varepsilon_{c, t} \\
\varepsilon_{m, t}
\end{array}\right)
$$

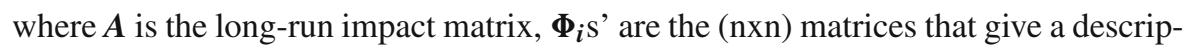
tion of the short-run dynamics, and satisfies the conditions to guarantee that the term $\sum_{i=0}^{\infty} \Phi_{i} v_{t-i}$ is stationary.

We can rewrite (9) in matrix terms in function of the vector of variables under analysis

$$
\left[\begin{array}{l}
l f_{t} \\
y-e_{t} \\
l_{t}-e_{t} \\
v_{t}
\end{array}\right]=\left[\begin{array}{lll}
a_{11} & a_{12} & a_{13} \\
a_{21} & a_{22} & a_{23} \\
a_{31} & a_{32} & a_{33} \\
a_{41} & a_{42} & a_{43}
\end{array}\right]\left[\begin{array}{l}
\psi_{t} \\
\theta_{t} \\
\omega_{t}
\end{array}\right]+\sum_{i=0}^{\infty} \Phi_{i}\left[\begin{array}{l}
\varepsilon_{s, t-i} \\
\varepsilon_{y, t-i} \\
\varepsilon_{c, t-i} \\
\varepsilon_{m, t-i}
\end{array}\right]
$$

The matrix $\boldsymbol{A}_{(4,3)}$ represents the long-run multipliers by the three permanent shocks, i.e. how each trend influences the variables in the long run. To identify our system, we have to add three identifying restrictions. From our identifying assumption $(\delta=0)$, we find from Eq. 6 that this implies that labour force is independent of both the technology and reallocation shocks in the long-run. This restriction implies that labour force is exogenous in the long-run, so from Eq. 2, we see that labour force is only driven by the labour supply trend. Moreover, it can be noted that if the production function (1) shows constant return to scale $(\beta=1)$, then productivity is fully explained by the technology trend. Note that we do not have to impose any further restrictions to identify the transitory shock. It is also noteworthy that we do not impose any restrictions on the short-term behaviour of the variables, or that the limit of the impulse response of the time series to the transitory shock becomes zero when the time horizon goes to infinity, so that its effects may be large in the short and medium term. In Sect.2 the cointegration relation for the three trends system is given by the market tightness relation. Its coefficients are described by the vector

$$
\beta^{\prime}=[0-\gamma-11]
$$


If we premultiply the parameter vectors in Eq. 6 by $\beta^{\prime}$ then we find that the resulting coefficients on $\psi_{t}, \theta_{t}$ and $\omega_{t}$ are all equal to zero. In terms of Eq. 10, the $a_{i j}$ coefficients must obey the same restrictions. We know that since $A_{(4,3)}$ is the matrix containing our $a_{i j}$ coefficients, the identifying assumption $(\delta=0)$ and the cointegration restrictions $\left(\beta^{\prime} A=0\right)$ result in:

$$
A=\left[\begin{array}{ccc}
a_{11} & 0 & 0 \\
a_{21} & a_{22} & 0 \\
a_{31} & a_{32} & a_{33} \\
a_{21} \gamma+a_{31} & a_{22} \gamma+a_{32} & a_{33}+a_{23} \gamma
\end{array}\right]
$$

The problem is uniquely determined: in addition to $\gamma$ and $\delta$, the other parameters of the theoretical model. In order to make the trend coefficients in (11) comparable with those in Eq. 6 we must transform the theoretical trends so that their innovations also have unit variances.

In order to compare the theoretical and empirical models, the vector of coefficients on $\psi_{t}$ in Eq. 6 is multiplied by $\sigma_{s}$, while $\psi_{t}$ is multiplied by $\frac{1}{\sigma_{s}}$, and analogously for the other trends. We see that there are six unknown parameters included in the theoretical expressions for the trend coefficients, $\left(\delta, \beta, \eta, \sigma_{s}, \sigma_{y}, \sigma_{c}\right)$.

Since $\boldsymbol{A}$ matrix is assumed to contain the structural parameters on the $(n-r)$ common trends, it must be orthogonal to the cointegration vector(s), $\boldsymbol{\beta}$. This implies the restriction $\beta^{\prime} A=0$, or, expressed using a selection matrix $\boldsymbol{A}_{0}$, chosen such that $\beta^{\prime} A_{0}=0$,

$$
A=A_{0} \pi
$$

where $\boldsymbol{A}_{0}$ is an $n \times k$ matrix with known parameters, chosen so that the innovations to the trends have an economic interpretation, ${ }^{16}$ and $\pi$ is a $(n-r) \times(n-r)$ matrix lower triangular. Computing the product, and setting the theoretical trend coefficients equal to the empirical in Eq. 11, some algebra calculations give us, the Beveridge curve trade-off parameter:

$$
\eta=\frac{a_{21}}{a_{11}} \gamma-1
$$

The returns to scale parameter

$$
\beta=\frac{a_{21}[\eta(1+\gamma)+1]-a_{11}(\eta-1)}{a_{21} \eta \gamma+a_{11}(1-\eta)}
$$

The labour supply elasticity

$$
\delta=0 \quad \text { (identifying assumption) }
$$

\footnotetext{
$\overline{16}$ A suitable choice is to use an orthogonal complement to $\beta$, (i.e. $\beta^{\prime} \beta_{\perp}=0$ ).
} 
Table 1 Estimated common trends coefficients

\begin{tabular}{llll}
\hline Variable & $\psi$ & $\theta$ & $\omega$ \\
\hline$l f_{t}$ & 0.621 & 0.00 & 0.00 \\
& $(0.194)$ & $(-)$ & $(-)$ \\
$y-e_{t}$ & -0.495 & 0.725 & 0.00 \\
& $(0.492)$ & $(0.348)$ & $(-)$ \\
$l_{t}-e_{t}$ & -0.113 & -1.169 & 0.259 \\
& $(0.0517)$ & $(0.594)$ & $(0.045)$ \\
$v_{t}$ & 0.346 & 0.120 & 0.259 \\
& $(0.147)$ & $(0.137)$ & $(0.045)$ \\
\hline
\end{tabular}

Note Standard errors are reported in parenthesis

The standard deviation of the supply labour trend innovation

$$
\sigma_{s}=a_{11}
$$

The standard deviation of the technology trend innovation

$$
\sigma_{y}=\frac{a_{22}[\eta(1-\beta \gamma+\gamma)+1]}{(1+\eta)}
$$

The standard deviation of the reallocation trend innovation

$$
\sigma_{c}=\frac{a_{33} \gamma a_{22}[\eta(1-\beta \gamma+\gamma)+1]}{a_{42}(1+\eta)}
$$

Unemployment, usually is positively affected by labour intersectoral reallocations as a response to aggregate shocks. Long-run effects on unemployment can be explained by hysteresis phenomena of negative (positive) aggregate demand shocks (Carlin and Soskice 1990). Therefore, the process can manifest a hysteresis system with many equilibrium rates of unemployment. ${ }^{17}$ Indeed, in the common trends model unemployment and vacancy dynamics attain at their long-run behaviour in which they show persistence paths, so that the model is consistent with a hysteresial process.

We analyse in detail the importance and the reaction at the permanent and transitory shocks that hit our system through impulse response functions and forecast error variance decomposition (FEVD). The interest is concentrated particularly on the reaction of unemployment and vacancy rates at specific shocks, and on the possible sources of persistence. Table 1 reports estimates of the long-run multipliers in the matrix $A$ in Eq. 11. The $a_{i j}$ estimates measure the long-run response of the variables from a unit shock to the orthogonal innovations in the three trends.

Table 1 shows the long-run effects on the variables arising from a unit shock to labour supply, technology and reallocation innovations (percentage values). For example, it

\footnotetext{
17 For details on other models where changes in aggregate demand can cause permanent changes in the rate of unemployment, see, among others, ( Hahn and Solow 1995; McDonald and Sibly 2001).
} 

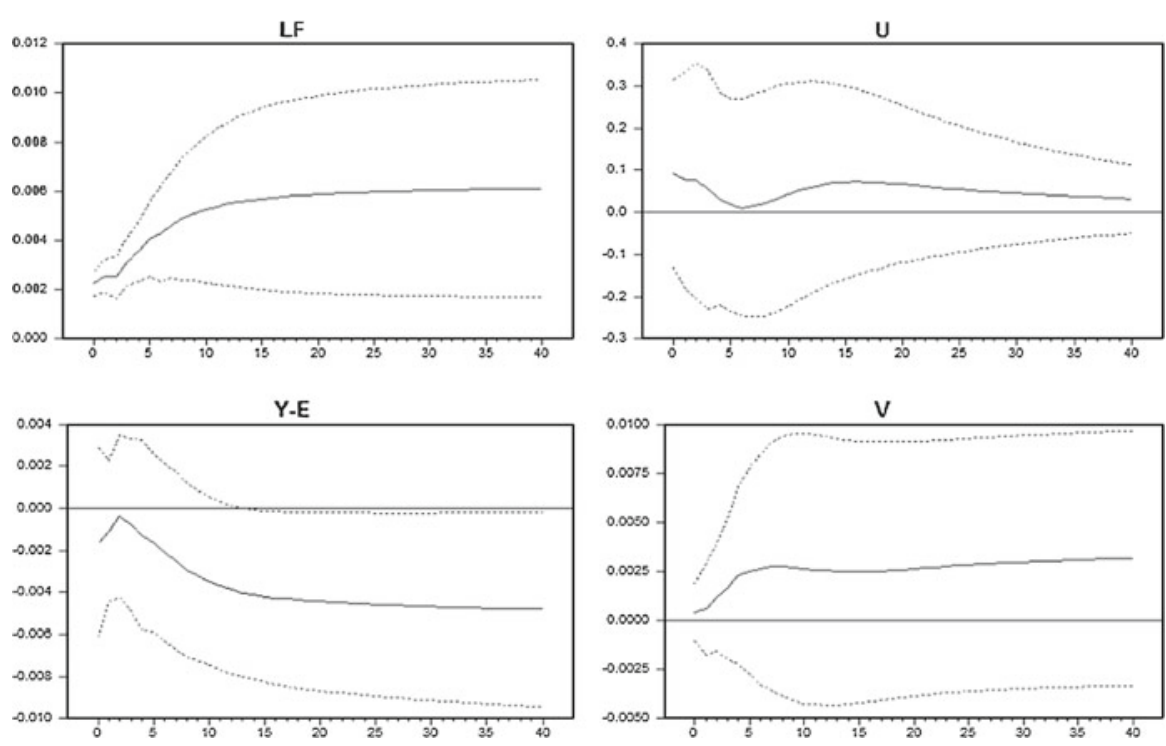

Fig. 2 IRF of the variable from a unit shock to the labour supply innovation

is noticeable that a unit shock to labour supply (i.e. an autonomous or policy-induced change in the labour-participation rate), raises labour force approximately by $0.6 \%$, has a negative long-run effect on unemployment of $-0.11 \%$, and a positive one on vacancy, since it may enhance job creation as, owing to the additional labour supply, opening of a vacancy for new jobs becomes less costly. According to these results, as pointed out by BD (1989, p. 59), it is possible that an exogenous increase in the labour supply is associated with some increases in employment, that is some jobs are created with the entry of new workers, or suppressed as some existing workers leave the labour force. Moreover, positive labour supply shocks may lead to lower unemployment if the long-run labour demand shift (e.g. via an increase in the output) is greater than the shift in the supply curve as long as the supply elasticity with respect to wage is sufficiently small. In this view, employment increases more than the labour force, thereby decreasing the unemployment rate.

The dynamic behaviour of the variables can be seen by the impulse responses in Figs. 2, 3, 4, and 5, where we provide the estimated impulse responses fluctuations for the four different shocks along with $95 \%$ confidence bands. Figure 2 displays the impulse responses of the various variables to a one-unit labour supply structural shock.

It is noteworthy that there is an increasing of unemployment in the short run, e.g. if the employment increases less than labour force. The long-run effects on the variables by technology shocks are shown in Fig. 3 .

Table 1 (second column) and Fig. 3 show the long-run responses of unemployment and vacancy to a technology shock. Observe that unemployment and vacancy respond in opposite directions, with unemployment falling by $1.17 \%$ and vacancy rising by $0.12 \%$, e.g. a technology shock induces an increase in labour productivity that raises the labour demand, and hence, through it, an increase of the vacancies posted by the 

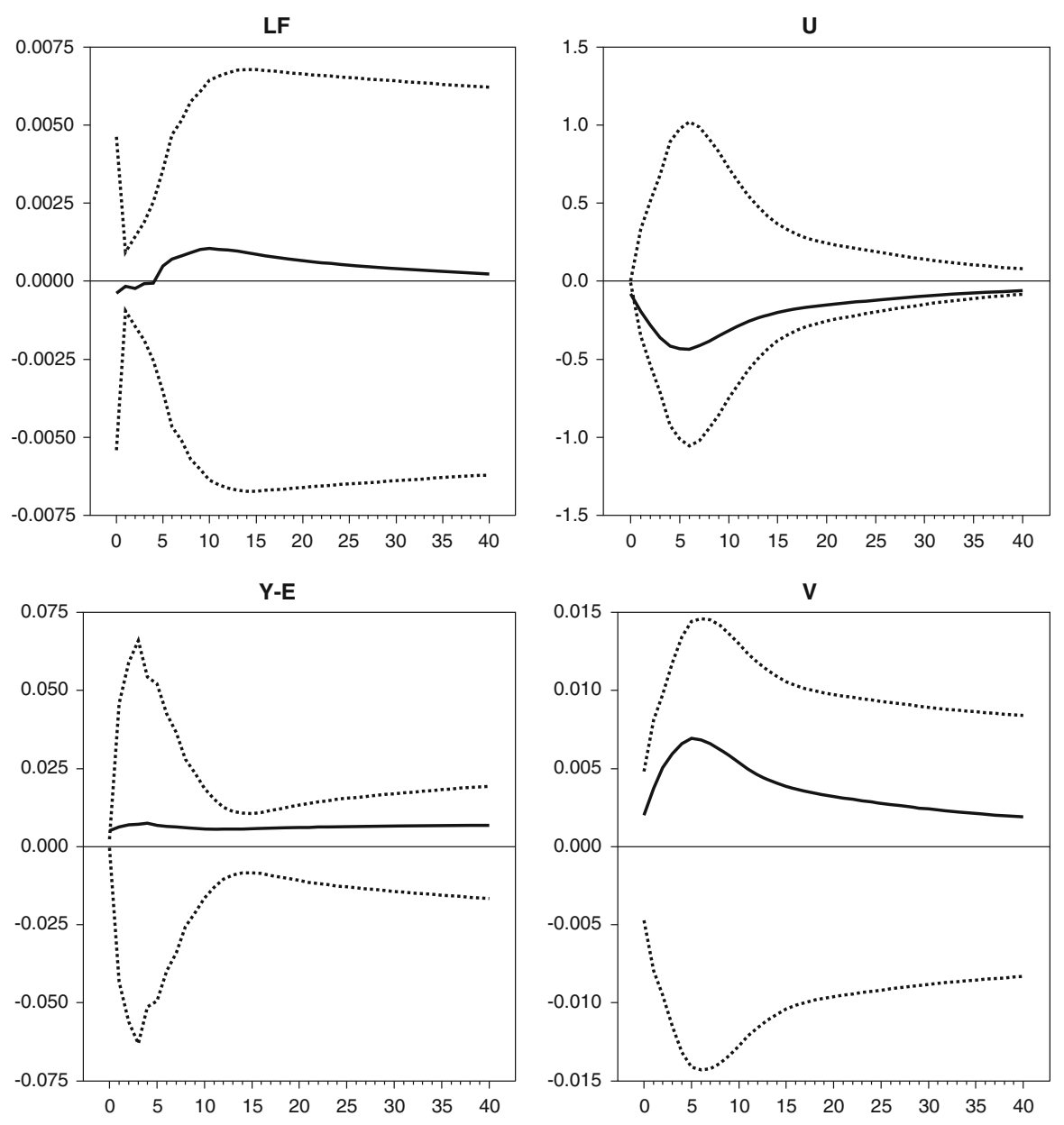

Fig. 3 IRF of the variables from a unit shock to the technology innovation

firms. The technology shocks of our model, with a note of caution, given the simplified production function (1), are consistent with the results of Shimer (2005) that finds technology inducing a negative correlation between unemployment and vacancies, so that they are consistent with a downward sloping Beveridge curve; in other words, a technology shock tends to reduce the unemployment rate as more workers obtain employment in the expanding sectors, and higher productivity firms post more vacancies. Therefore, it tends to increase the transition rate from unemployment to employment, and to decrease the transition rate from employment to unemployment. Therefore, vacancies and unemployment should have negative correlation.

Figure 4 displays the impulse responses to a reallocation shock. Positive aggregate reallocation shocks lead to job destruction and an increase in unemployment, and leading over a period to post vacancies, if the job destruction created by the firms which are negatively hit by the shocks, prevail on the creation of additional jobs due to 

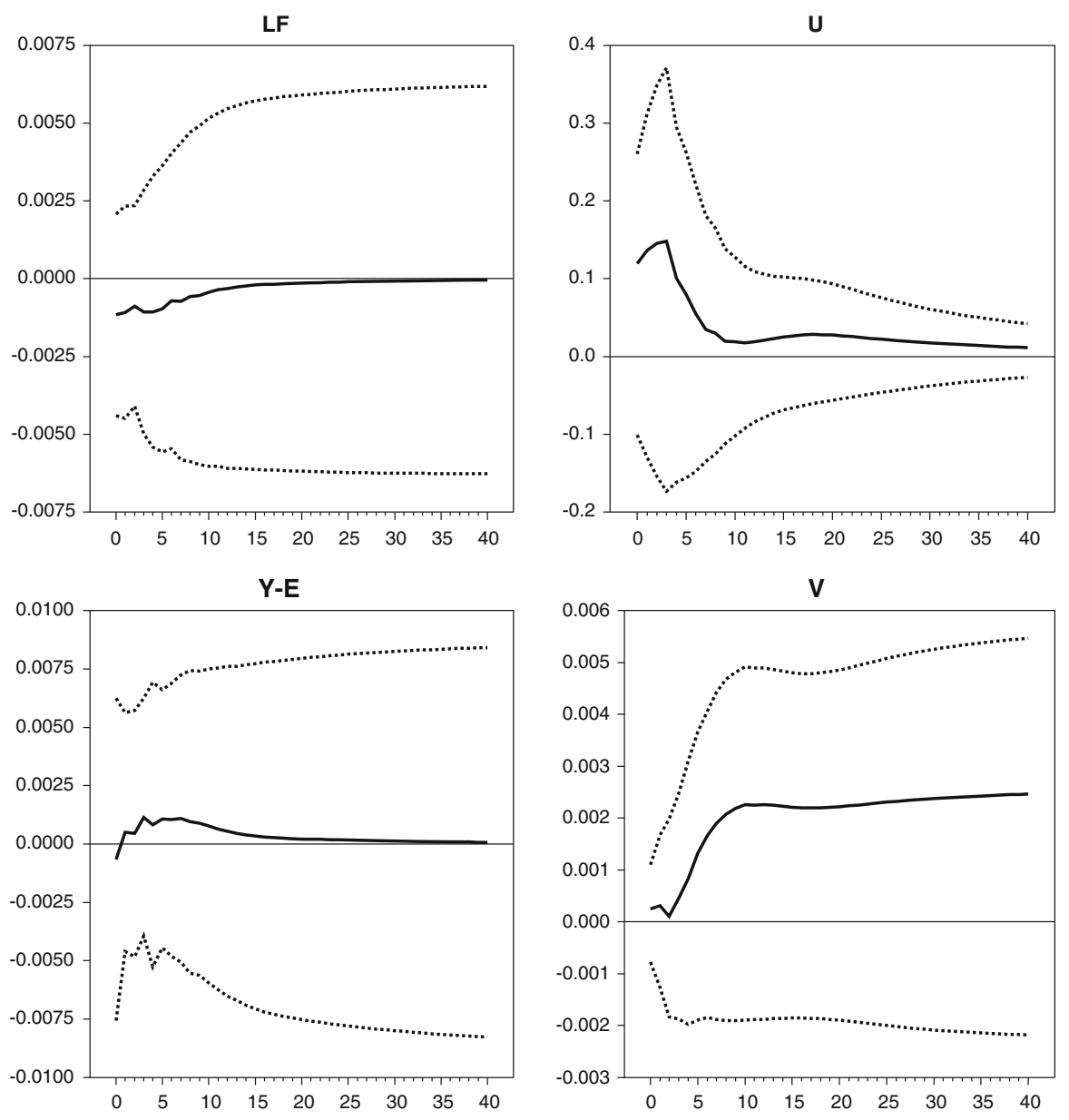

Fig. 4 IRF of the variables from a unit shock to the reallocation innovation

sectors and firms where the shocks have positive effects. At aggregate level, a negative demand shock will result in lower profitability of jobs and therefore in an increase of job destruction, and a decrease of job creation. Reallocation effects, if persistent, can shift the curve from the origin.

In the model, reallocation shocks cause adjustment processes of job vacancies, and unemployment rather sluggish. As in Braun et al. (2009), the reallocative shock has a short-run negative effect on labour productivity and no significant long-run effects. As argued by Barlevy (2002), the literature (see Hall 1991, 2000; Mortensen and Pissarides 1994, for example), has developed models where recessions are associated with a more efficient allocation of resources by 'cleansing' out-less efficient matches and redirecting resources into more productive uses, but his model gives rise to a countervailing 'sullying' effect that works against the cleansing effect, since workers 


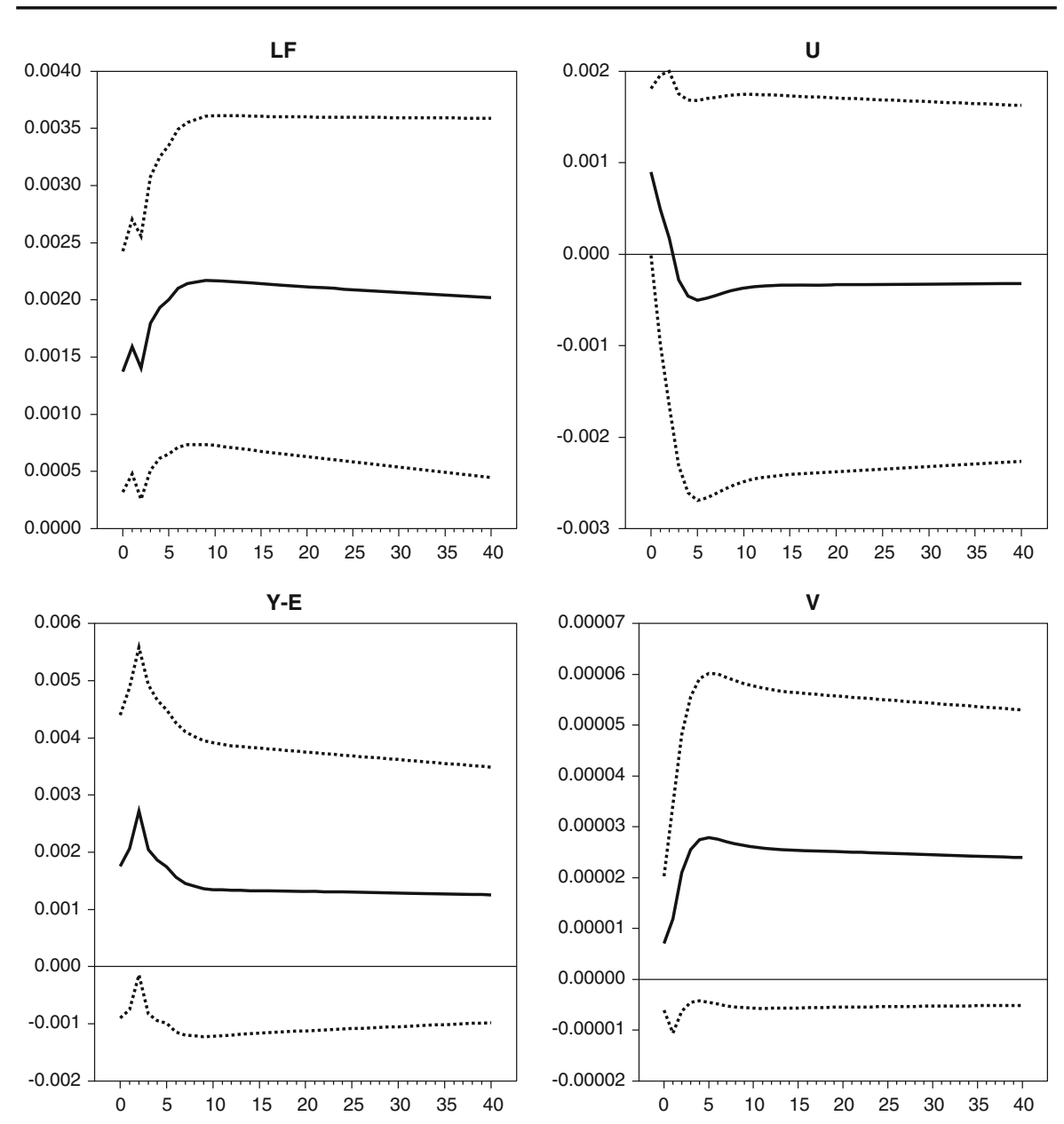

Fig. 5 IRF of the variables from a unit shock to the transitory innovation

reallocate into their most productive uses more slowly during downturns than during booms.

The dynamic responses of unemployment and vacancy to the transitory innovation are shown in Fig. 5. This disturbance, identified as a market-tightness shock, leads to an increase of the $v-u$ ratio in the short run, peaking within a year, after which the ratio displays steadiness over time.

Looking at Fig. 5 and at the short-run impact matrix $R(0)$ in Table 2 (last column), the transitory shock initially raises both unemployment and vacancy and later they move in opposite direction, increasing the $v-u$ ratio, with vacancies that seem to be less sensitive to short-run business fluctuations. Sluggish propagation mechanisms lead to long-lasting effects of transitory shock, showing some degree of inertia of the economic adjustment. Fujita and Ramey (2007) and Shimer (2007) have noted sluggishness, in the vacancy dynamics adjustment is likely due also to the presence 
Table 2 Short-run impact matrix $R(0)$

\begin{tabular}{lrrrr}
\hline Variable & \multicolumn{1}{c}{$\psi$} & \multicolumn{1}{c}{$\theta$} & \multicolumn{1}{c}{$\omega$} & \multicolumn{1}{c}{$\varepsilon_{m}$} \\
\hline$l f_{t}$ & 0.2244 & -0.0393 & -0.1163 & 0.1378 \\
$y_{t}-e_{t}$ & -0.1631 & 0.5072 & -0.0659 & 0.1757 \\
$l_{t}-e_{t}$ & 0.9076 & -0.8116 & 0.1196 & 0.0900 \\
$v_{t}$ & 0.0038 & 0.2002 & 0.0243 & 0.0069 \\
\hline
\end{tabular}

of sunk costs for job creation, that is, firms with a higher rate of worker turnover tend to post vacancies at a higher rate, and thus, job positions become more valuable once they are created.

The increase of the labour market tightness, although the persistence of the transitory innovation shock, is likely attributable to demand shocks that improve the labour productivity through which it induce small movements along a downward sloping curve.

Estimating the common-trend model allows for the decomposition of the observed Beveridge curve into underlying permanent and transitory components. The long-run Beveridge curve is derived from the estimates of $\boldsymbol{A}$, which is the behaviour of unemployment and vacancy in the vector $\boldsymbol{x}_{\boldsymbol{t}}$ due to the permanent disturbances, interpreted as the long-run forecast of the variables, expressed as

$$
\begin{aligned}
& u_{L}=\lim _{h \rightarrow \infty} E_{t} u_{t+h}=u_{0}+a_{i j} \tau_{t} \\
& v_{L}=\lim _{h \rightarrow \infty} E_{t} v_{t+h}=v_{0}+a_{i j} \tau_{t} \quad i=3,4 j=1,2,3
\end{aligned}
$$

capturing the values to which the series are expected to converge as long-run behaviour, once the effects of transitory shocks have died out. ${ }^{18}$ This behaviour, interpreted as the long-run Beveridge curve, can be computed as

$$
x_{0, i}+A_{i} \sum_{j=0}^{t-1} \varphi_{t-j} \quad i=u_{t}, v_{t}
$$

where $\varphi_{t}$ is the vector of the structural shocks of the common trends. Then, the estimated long-run unemployment and vacancy series derived from the model are computed as

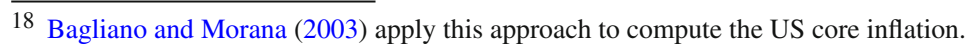




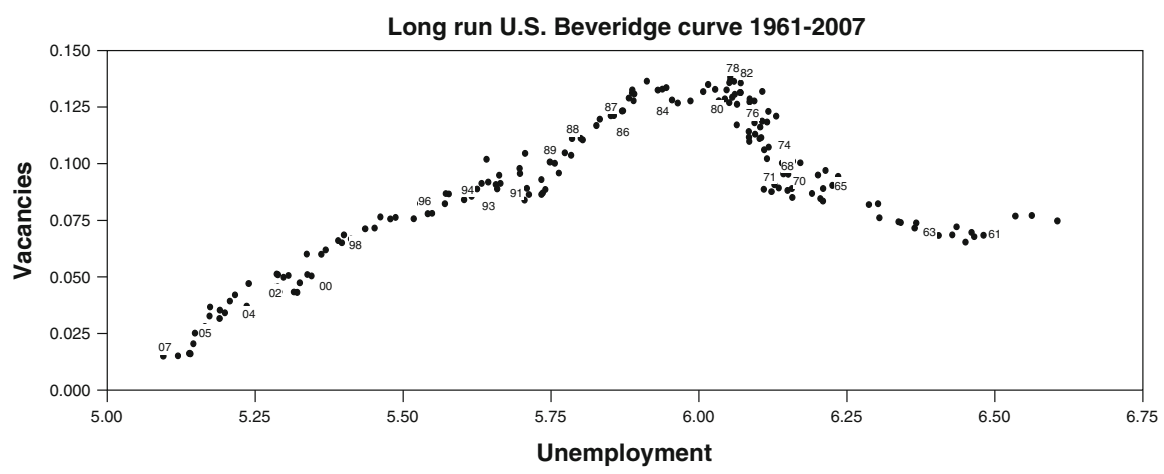

Fig. 6 Multivariate structural decomposition of the long-run US Beveridge curve

$$
\begin{aligned}
& \hat{u}_{L}=\hat{u}_{0}+\hat{a}_{31} \hat{\psi}_{t}+\hat{a}_{32} \hat{\theta}_{t}+\hat{a}_{33} \hat{\omega}_{t} \\
& \hat{v}_{L}=\hat{v}_{0}+\hat{a}_{41} \hat{\psi}_{t}+\hat{a}_{42} \hat{\theta}_{t}+\hat{a}_{43} \hat{\omega}_{t}
\end{aligned}
$$

so that these relations capture the long-run effects on the variables of the three identified permanent disturbances, and bear the interpretation of the long-run unemployment-and-vacancy forecast, when all transitory fluctuations in these two variables have vanished, suggesting that the long-run Beveridge curve is due to the propagation of shocks to the economy rather than a particular source of impulses. However, the cyclical component is

$$
\Phi(L) v_{t}=\lim _{h \rightarrow \infty} \sum_{i=1}^{h}\left(\Delta \hat{x}_{t+k \mid t}-E\left(\Delta x_{t}\right)\right)
$$

simply computed as

$$
\begin{aligned}
& u_{c}=u_{t}-\hat{u}_{L} \\
& v_{c}=v_{t}-\hat{v}_{L}
\end{aligned}
$$

where the cyclical component is determined by both the innovations of the system, permanent and transitory, so that the permanent innovations also affect transitory dynamics.

Figure 6 shows the long-run component of the curve, indicating an increased efficiency implied by an evident inward movement beginning in the late 1980 s until today. The chart suggests significant changes in the efficiency of the aggregate job matching process in the US over the past four decades, showing a reduced efficiency and a deterioration of the job-matching process in the 1970s and the early 1980s, implied by some evidence of outward shifts of the curve in these years and then improvements onward. These results (various authors identified similar results, see e.g. the findings of Abraham (1987), Katz and Krueger (1999), and Valletta (2005), inter alia), reflect an improved US labour market performance over the last two decades. 


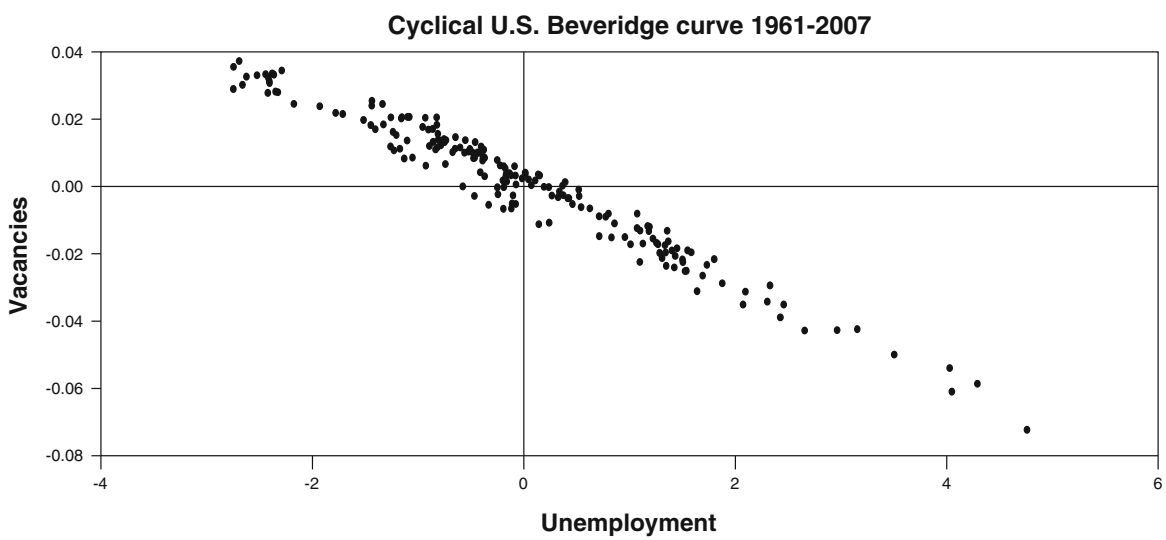

Fig. 7 Multivariate structural decomposition of the cyclical US Beveridge curve

Table 3 FEVD of unemployment

\begin{tabular}{lllll}
\hline Quarter & $\psi$ & $\theta$ & $\omega$ & $\varepsilon_{m}$ \\
\hline 1 & 0.159 & 0.127 & 0.277 & 0.436 \\
4 & 0.039 & 0.439 & 0.132 & 0.390 \\
8 & 0.016 & 0.628 & 0.062 & 0.294 \\
16 & 0.020 & 0.677 & 0.042 & 0.261 \\
24 & 0.031 & 0.675 & 0.039 & 0.255 \\
32 & 0.036 & 0.674 & 0.038 & 0.251 \\
$\infty$ & 0.535 & 0.437 & 0.028 & 0.000 \\
\hline
\end{tabular}

Note In column 1-3 are reported the values by the permanent shocks, in column 4 by the transitory shock

Figure 7 shows a scatter plot of the relationship between the cyclical component of unemployment and vacancy, the short-run Beveridge curve. The correlation between the two components is very high, -0.98 , between 1961 and 2007. Indeed, BD in their seminal study concluded that at business cycle frequencies, shocks generally drive unemployment and vacancy rates in the opposite direction.

Tables 3 and 4 show FEVD of unemployment and vacancy, aiming at assessing the relative importance of the four shocks to the Beveridge curve dynamics. Number of quarters ahead measure the fraction of the forecast error attributable to each disturbance.

In Table 3, for short-time horizons (within the first year), technology and transitory shocks explain roughly $84 \%$ of unemployment error variance; in the long run, the weight of the market tightness shock decreases whilst the roles of technology and labour supply increase. Labour supply shock accounts only for a small fraction of unemployment variance in the short run, but increases in the long run (almost 54\%), and transitory shocks account for a long-time horizon, showing some persistence of the $v-u$ ratio. Reallocation shock has its major effects within one year; later, the supply factors begin to have more incidence on unemployment. Note that contribution of 
Table 4 FEVD of vacancy

\begin{tabular}{lllll}
\hline Quarter & $\psi$ & $\theta$ & $\omega$ & $\varepsilon_{m}$ \\
\hline 1 & 0.021 & 0.493 & 0.007 & 0.479 \\
4 & 0.037 & 0.641 & 0.003 & 0.319 \\
8 & 0.080 & 0.679 & 0.024 & 0.217 \\
16 & 0.119 & 0.647 & 0.068 & 0.166 \\
24 & 0.154 & 0.604 & 0.097 & 0.144 \\
32 & 0.193 & 0.558 & 0.123 & 0.126 \\
$\infty$ & 0.594 & 0.074 & 0.332 & 0.000 \\
\hline
\end{tabular}

technology shock to the cyclical fluctuations of unemployment account roughly for $60 \%$.

Table 4 shows FEVD of vacancy. At business cycle frequencies, technology and transitory shocks explain almost $90 \%$ of the vacancy variance; for longer horizons, labour supply and reallocation shocks increase its weight, accounting roughly for 60 and 33\% of variance, respectively. These findings are consistent with the results of Mortensen and Pissarides (1999), in which job reallocation shocks, in both USA and Italy, do not reverse shortly after they occur, where there is large persistence in job creation and job destruction, with persistence rates for the latter being slightly higher than the former.

\section{Beveridge curve for Italy: the aggregate analysis}

\subsection{Cointegration analysis}

In Italy, recent labour legislation changes (the so-called Treu Act 1997, and Biagi Act 2003) have been introduced to try to ease the regulation of temporary work, to introduce the 'job on call', 'job sharing' figures and, in general, to reduce the mismatch phenomena and to liberalize Italian labour market. Some results on the unemployment rate are evident; in the last years it has been decreasing over time, even though this improvement is due overall to an increasing number of temporary work contracts.

Italian data for vacancies derive from ISFOL-CSA survey. ${ }^{19}$ Owing to the absence of official data on vacancies, there are not many empirical studies on the dynamics and the relations of the Beveridge curve in Italy (see e.g. Bragato 1990; De Stefanis and Fonseca 2007; Mocavini and Paliotta 2000). Figure 8 shows IT Beveridge curve, where inward shift of the curve from the late 1990s until today can be noted, indicating some improved efficiency for the Italian labour market in the last decade, but from the visual inspection of the graph the theoretical negative relationship between unemployment and vacancy is more evident in the 1990s rather than in the early 2000s.

19 In Italy, there are no official vacancy data. Available sample for vacancy is from 1980 to 2006 . We collected labour market data of the Italian Statistical Office from 1982 to 1992 to let the chaining with the new survey that starts from 1992:4. 


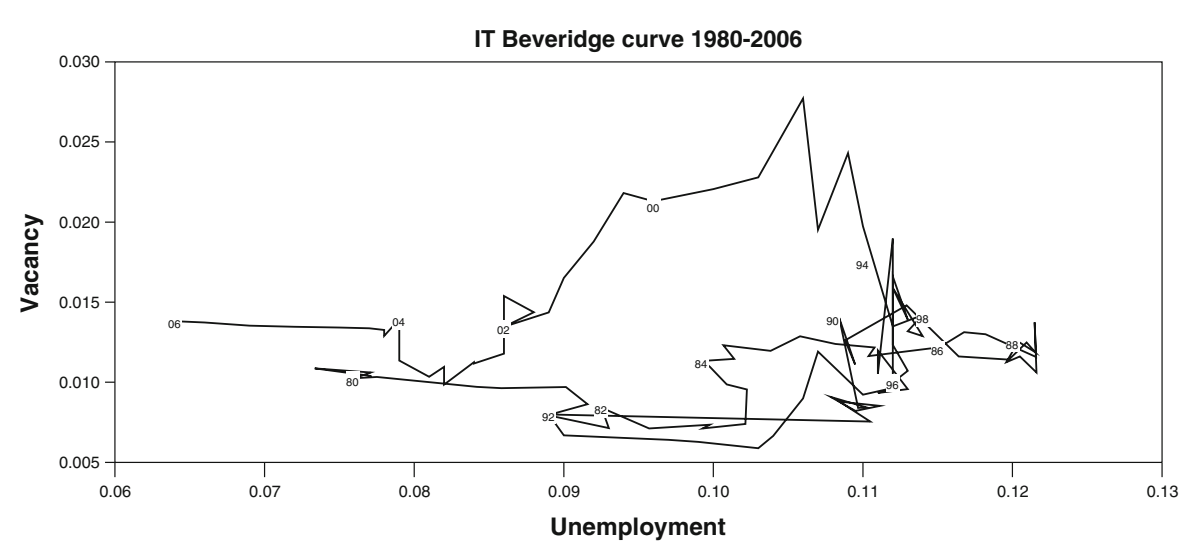

Fig. 8 IT Beveridge curve

Johansen's cointegration analysis was applied to a VAR with four variables and three lags. The results of the cointegration tests are shown in Appendix Table A6.

When the Bartlett correction factor of the rank test statistic is considered, the null of non-cointegration can be rejected in favour of the alternative of the existence of one cointegration vector among the four variables, i.e. $r=1 .^{20}$ With a cointegration rank, $r=1$, there are $k=n-r=3$ common stochastic trends that drive the system. Overidentifying restrictions on the cointegrating vector were applied and accepted by LR test. ${ }^{21}$ For Italy, the empirical counterpart of the relation (4) of the theoretical model, takes the form of the restricted cointegration relationship identified as

$$
v_{t}-u_{t}=1.16\left(y_{t}-e_{t}\right)
$$

the $v-u$ ratio stationary relationship shows an elasticity almost proportional with respect to labour productivity, confirming that labour productivity shocks, also for Italy, are consistent with a downward sloping Beveridge curve. Recursive analysis showed no serious problems of the model, given the beta constancy tests reported in Appendix Figs. 22 and 23, even though there were some instability around the early 1990s, likely due also to an important change of the statistical survey method of labour market data by the Italian Statistical Office.

\subsection{The common-trend analysis}

Now we use the cointegration properties found in the first stage of the analysis to identify the permanent and transitory shocks of the SVECM model. The system is driven by three common stochastic trends. In Table 5, the long-run multipliers are reported

\footnotetext{
20 A shift dummy variable for 1992:4 was inserted in the model to account for the change of the labour market data survey by Italian Statistical Office. A simulation of the asymptotic critical values has been carried out. It does not lead us to reconsider the choice of cointegration rank. See Appendix D and Table A7.

21 LR test is $\chi^{2}(3)=4.56, P$-value* $[0.207]$.
} 
Table 5 Estimated common trends coefficients

\begin{tabular}{llll}
\hline Variable & $\psi$ & $\theta$ & $\omega$ \\
\hline$l f_{t}$ & 0.443 & 0.000 & 0.000 \\
& $(0.145)$ & $(-)$ & $(-)$ \\
$y-e_{t}$ & -0.131 & 0.204 & 0.000 \\
& $(0.088)$ & $(0.046)$ & $(-)$ \\
$l_{t}-e_{t}$ & -0.331 & -0.190 & 0.119 \\
& $(0.094)$ & $(0.065)$ & $(0.028)$ \\
$v_{t}$ & -0.030 & 0.052 & 0.119 \\
& $(0.051)$ & $(0.027)$ & $(0.028)$ \\
\hline
\end{tabular}

Note Standard errors are reported in parenthesis
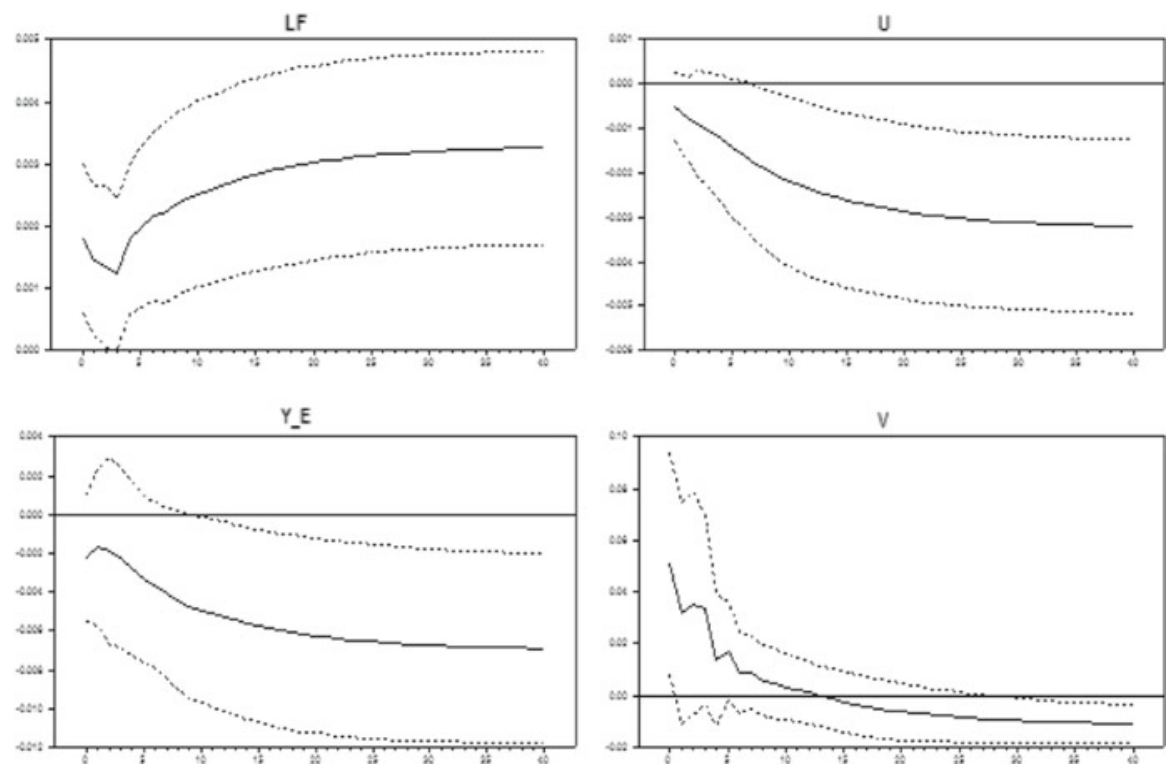

Fig. 9 IRF of the variables from a unit shock to the labour supply innovation

from the three permanent shocks, identified as a labour supply, technology, and reallocation shocks, with the latter, like for US, which affects unemployment and vacancy in the same direction, and through its effects (e.g. income effects), causes aggregate demand expansions or contractions. The long-run dynamics of the variables to the three disturbances are reported in the Figs. 9, 10 and 11.

The shock response from the first common trend (Table 5, first column) - the labour supply shock - shows permanent negative effects on unemployment and vacancy (with a small long-run multiplier and no statistically significant): an exogenous increase in the labour supply may enhance job creation, since the additional labour supply makes the opening of a vacancy for a new job less costly. The long-run negative reaction of vacancy could be linked to the hypothesis that a larger number of job seekers reduce 

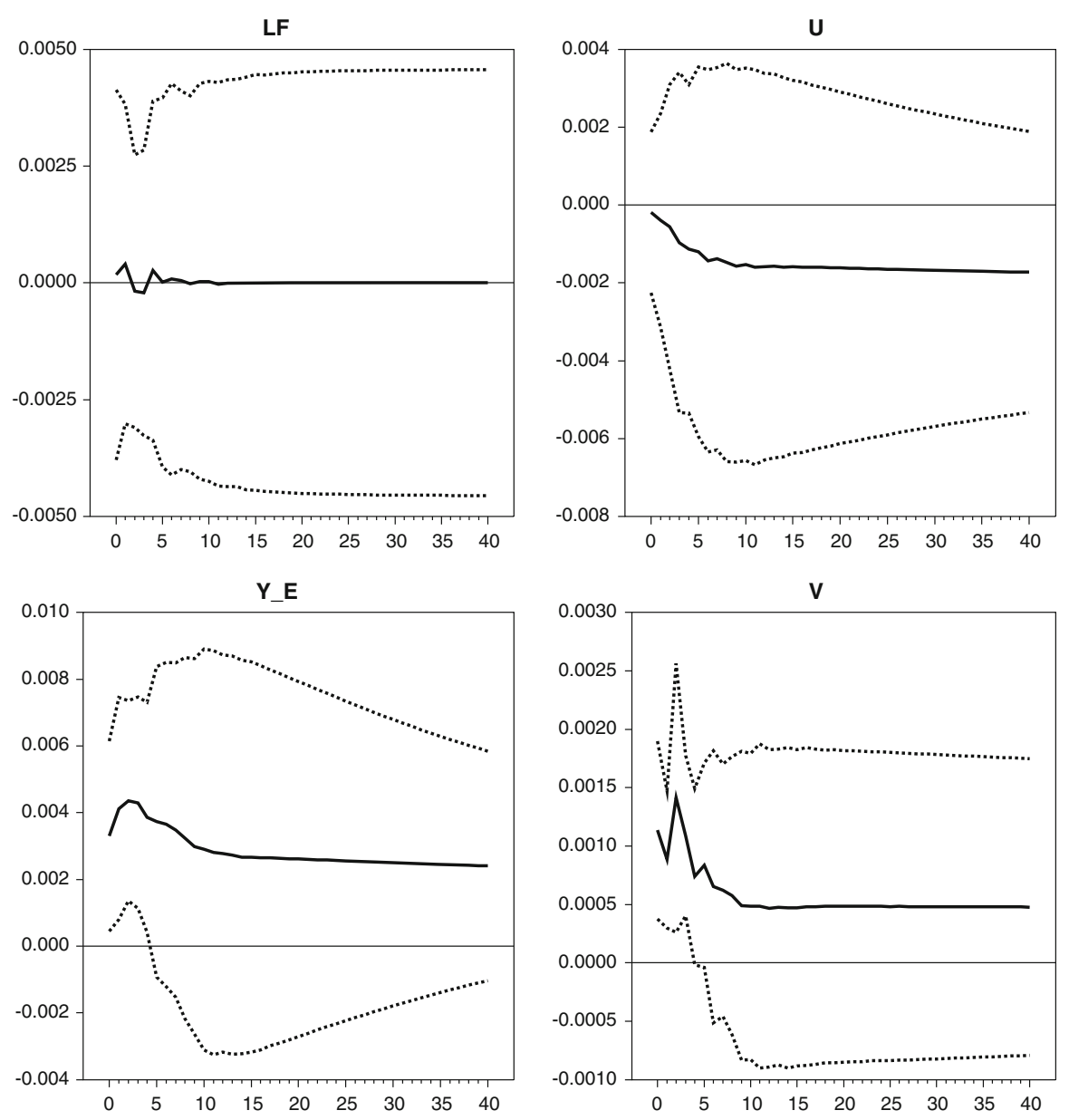

Fig. 10 IRF of the variables from a unit shock to the technology innovation

the number of job vacancies, even though in the short-medium run (within two years) the response of vacancies is positive (see Fig. 9). Labour supply shocks can be caused, other than changes in the working age population, also by policies that induce changes in the labour participation rate. Recent institutional innovations in the Italian labour market could have induced changes in the labour participation rate. The long-run impact of a technology shock on unemployment is negative, driving a decrease of job destruction (or a less increase) and an increase of job creation. The long-run multiplier of technology common trend, if compared with US is not very strong, showing that in Italy, technology plays a small role for the improvement of the employment.

Aggregate reallocation shocks have moderate positive long-run effects on unemployment (Table 5, third column, Fig. 11), and on job vacancies. Owing to tastes, technology or institutional changes, firms hit by positive idiosyncratic shocks expand their production, whereas other firms are hit by adverse shocks and are bound to 

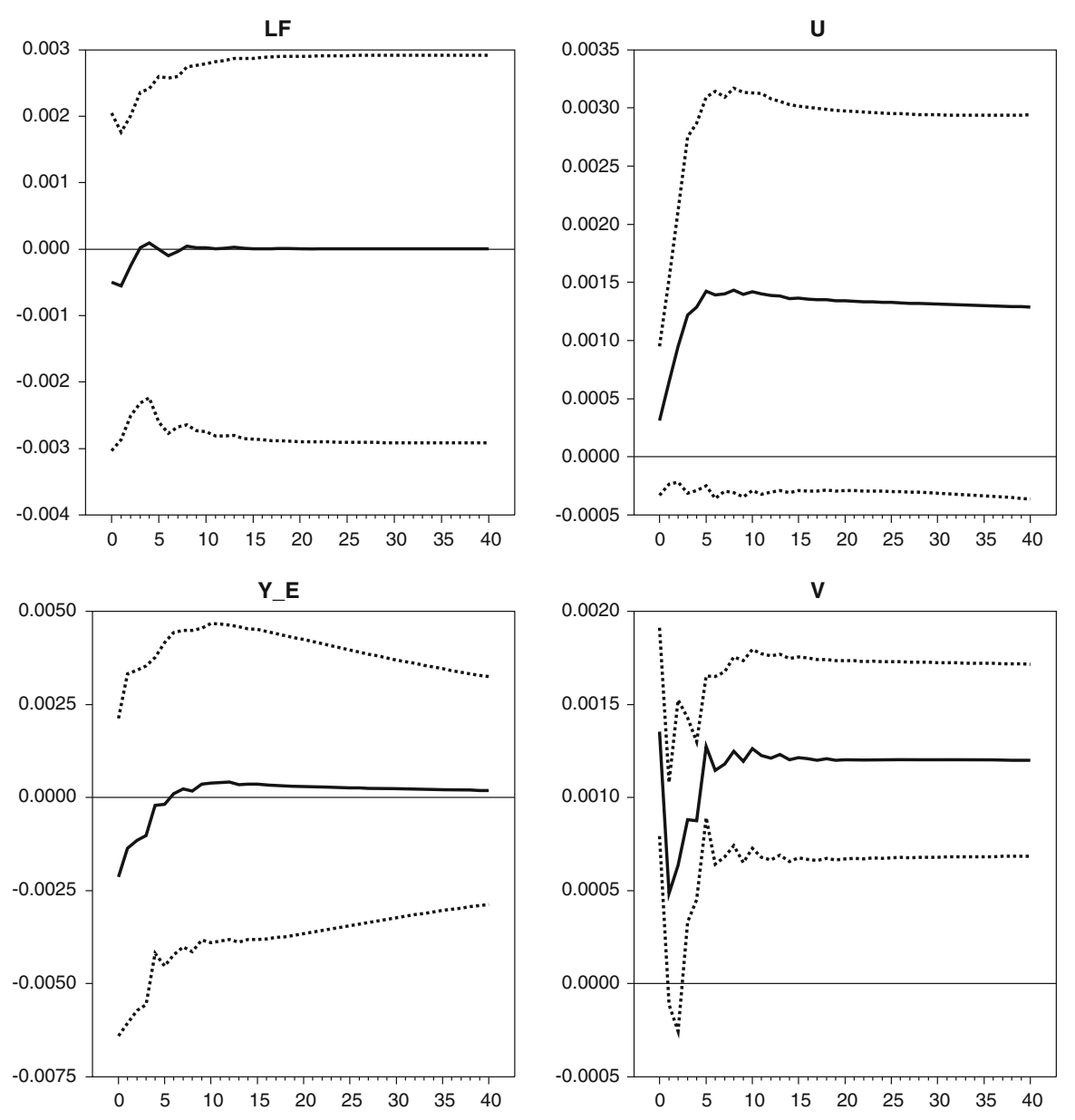

Fig. 11 IRF of the variables from a unit shock to the aggregate reallocation innovation

downsizing. At aggregate level, all these idiosyncratic shocks lead to a reallocation of production amongst the firms, and at macro level, these shocks take the form of aggregate reallocation shocks, i.e. the introduction of government incentives which give fiscal advantages to firms that invest in $\mathrm{R} \& \mathrm{D}$, or the introduction of an environmental tax that favour firms with a clean production technology. A positive reallocation shock can lead to increase unemployment if the job destruction prevails on the job creation. If the shocks hit all the firms in the same direction, then at the macro level, we have an aggregate negative or positive demand shock. The reallocation process takes time and resources to hire workers, and therefore, it is a costly process implying an increase in the unemployment rate.

Figure 12 displays the IRF to the transitory shock. Looking at the figure, a decreasing $v-u$ ratio is likely due to an increase in the separation rate that reduces wages. The graph displays also the sluggish adjustment process of unemployment leading to quite long lasting effects of the transitory shock, and this may reflect a rather high degree of 

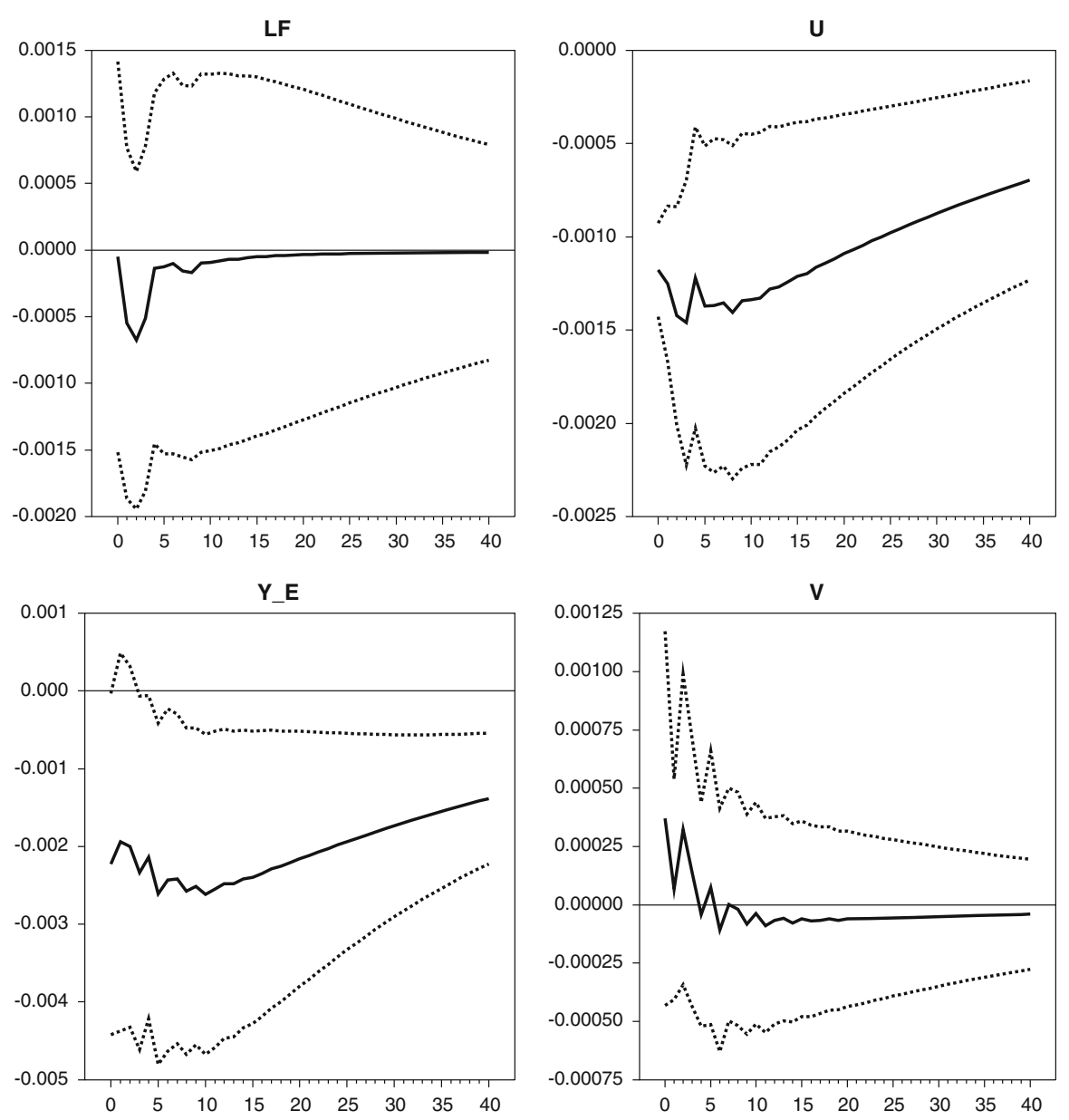

Fig. 12 IRF of the variables from a unit shock to the transitory innovation

inertia of the Italian labour market. Indeed, from FEVD analysis (Appendix Table A8), it can be noted that transitory innovations are the main contributor at horizons of two years or less, and at 8 -year horizon, they account for $27 \%$ of the unemployment rate variability.

Figure 13 displays the long-run Beveridge curve obtained from the model, and entails inward movements from the early 1990s. Figure shows the long-run curve in which it is possible to note two dynamic behaviours of the Beveridge curve for the 1980s, and the early 1990s and the 2000s, with the first decade showing a more sluggish dynamics of inward shifts, likely due to a more rigid labour market in this period. It is worth pointing out that the major enhancements of efficiency were from the early 1990s to early 2000s; afterwards the curve shows steadiness in the space $u-v$. Likely, these movements are due to labour supply and technology shocks, induced by institutional reallocation shocks of the Italian labour market occurred in those years 


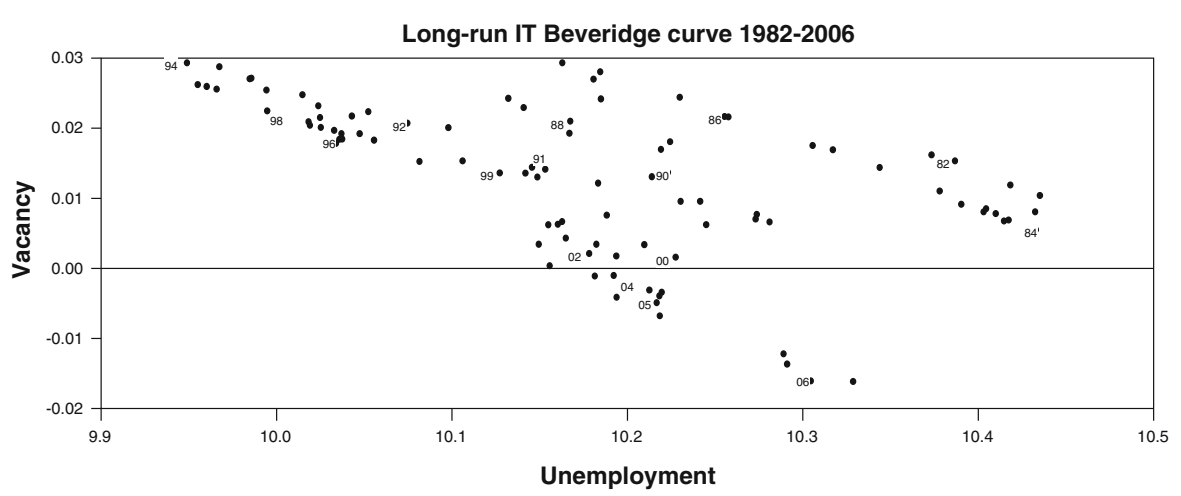

Fig. 13 Multivariate structural decomposition of the long-run IT Beveridge curve

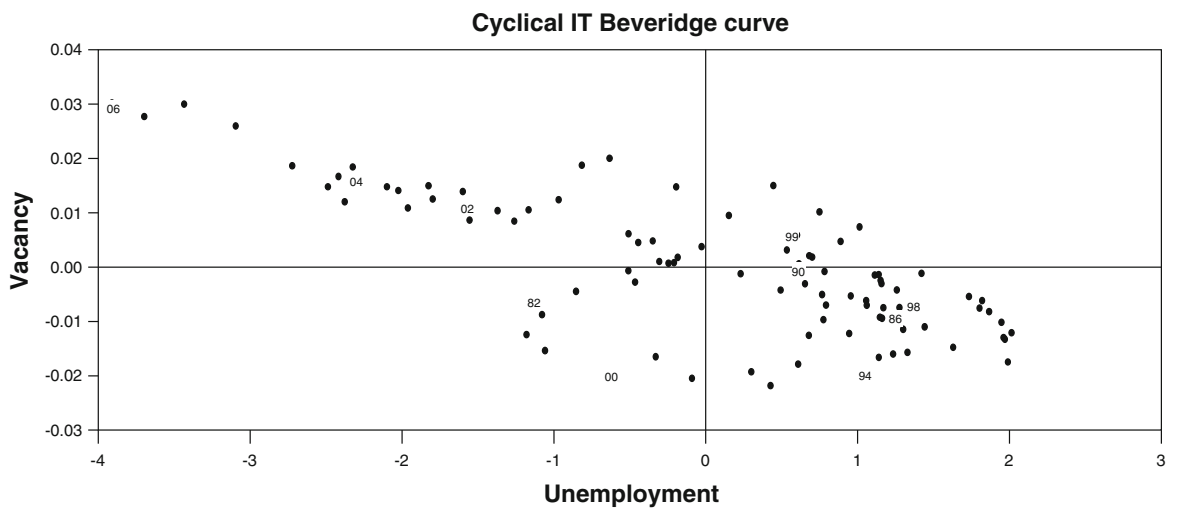

Fig. 14 Multivariate structural decomposition of the cyclical IT Beveridge curve

(Appendix Tables A8 and A9 report the FEVDs of unemployment and vacancy). It is noteworthy that unemployment error variance is explained in the long-run approximately for $75 \%$ by two permanent shocks, i.e. labour supply and technology, and for $25 \%$ by reallocation shock, confirming the importance of supply factors to explain the structural unemployment. Vacancy error variance is explained in the first year roughly for $96 \%$ by technology and reallocations innovations, and in the long-run reallocation shock is the most important factor explaining vacancy variability accounting for $81 \%$. The results confirm the view of various authors that there is no a single cause for the rise in unemployment. We find that different shocks can explain unemployment at different time horizons.

Figure 14 displays the short-run IT Beveridge curve, where it can be noted an efficiency improvement of the labour market since the early 2000s, likely due to a moderate dynamics of the aggregate demand in this period, whereas for the 1980s until the early 1990s, the job-matching process displays a deterioration, in part likely due to the high union density and to wage rigidities causing lack in the labour demand. 


\section{Summary and conclusion}

In this article we present a comparison of the US and Italian Beveridge curve: the cointegration analysis shows that there is one stationary relationship among the variables in both the countries. Based on a small model of the labour market, we can identify a 'market tightness' equilibrium relation. In both the labour markets, three permanent shocks were identified; in both the countries, two of them affect unemployment and job vacancies in opposite directions. We argue that there are some sources of hysteresis in both countries: technology and reallocation shocks could have permanent effects on unemployment through modifications of equilibrium unemployment rate that could generate a macroeconomic multiple equilibria system. The long-run US Beveridge curve shows inward movements in the last two decades, reflecting an improved performance of the US labour market in these years, due to technology and labour supply shocks that, in connection with market tightness shocks, caused also inward movements of the curve at business cycle frequencies through increases of the $v-u$ ratio.

The analysis of the Italian Beveridge curve shows that the permanent effects of the labour supply and technology are not so strong like in US, and reallocation shocks have an important role for unemployment also in the long run. In particular, the latter affecting unemployment and job vacancies in the same direction cause the reallocation processes to be long and costly in terms of employment, until unemployment could start to decrease again. It is noteworthy that technology is important in both countries to explain unemployment variability. Labour supply shocks are the most important factor moving US unemployment in the long run, likely due to a less sluggish labour market in this country with respect to Italy where reallocation shocks explain a major portion of unemployment variance in the long-run with respect to the labour supply trend, likely due to various institutional and structural changes occurring since the 1980s that have induced firms to reallocate their production.

In both countries, data show a downward trend, since the 2000s, of help-wanted ads due to the increasing of the Internet as alternative source of job search, which has substantially reduced employers' reliance on traditional help-wanted advertisement, modifying the dynamics of the Beveridge curve in the recent years. Recruitment is an important process of searching and selecting qualified people for a specific job by a company or an organization, and can be performed through the use of internet technology to attract job seekers and companies, as an alternative of traditional recruitment, such as advertisement in newspaper or television which are far more expensive. The growing importance of Internet job listings improves not only the matching mechanism, but also decreases the help-wanted index to the true vacancies. However, even though Internet ads are not included in the sample data, from the long- and short-run Beveridge curves' graphics, we can note that it is likely that the increase in the flow of information on job openings, made possible by the Internet, has reduced in the recent years both structural and frictional unemployment, reduced the duration of job vacancies, and hence caused inward shifts of the Beveridge curve. 
Acknowledgements The authors thank Anders Warne for his helpful comments and suggestions on an early draft. The usual disclaimer applies. Any remaining errors are ours. The authors are grateful to Michele Cuppone for kindly providing us with the Italian vacancy data survey of Isfol-CSA.

\section{Appendix}

\section{A1 Data sources}

The original sources for data are FRED database available on the Federal Reserve of St. Louis website for the US: the standardized unemployment rate (by the U.S. Bureau of Labor Statistics, BLS), GDP, civilian labour force, total civilian employment, total nonfarm payrolls employment and the Conference Board help-wanted advertising index as proxy for vacancies data. Vacancy rate is obtained dividing helpwanted index data by labour force. Italian Statistical Office, ISTAT, (Quarterly Labour Force Survey) for the Italian variables labour force, employment, unemployment rate, GDP (Quarterly National Account), and ISFOL-CSA (Istituto per lo sviluppo della formazione professionale dei lavoratori, Rome, and Centro Statistica Aziendale in Florence) for the Italian vacancy survey data on the help-wanted advertisements published in some important daily newspapers. All the variables are seasonally adjusted (Fig. 15).

\section{A2 The production function}

Following Hansen and Warne (2001), we introduce the production function and the effect of the omission of the input capital from the model. The production process is represented by a Cobb-Douglas production function with two inputs, labour and capital, reported in loglinear form with labour augmenting technological progress (the scale parameter $a_{t}$ )

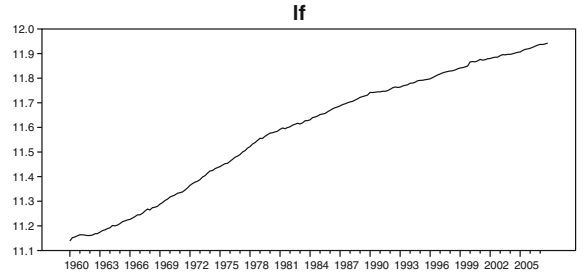

y-e

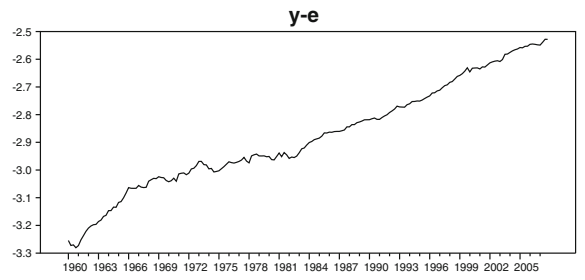

Fig. 15 The US variables under analysis

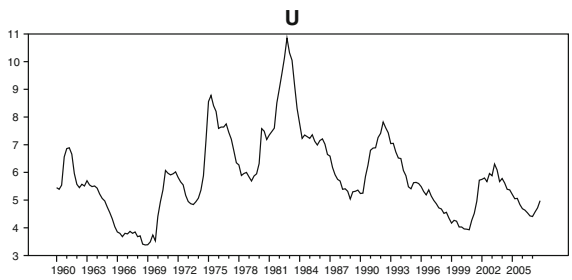

v

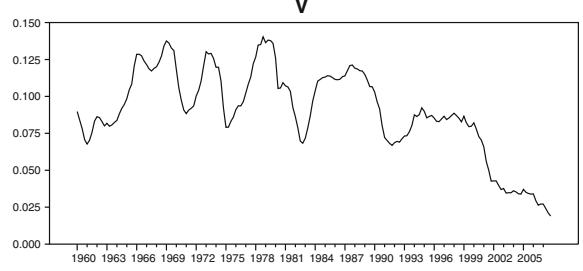




$$
y_{t}=\beta_{1}\left(a_{t}+e_{t}\right)+\beta_{2} k_{t}, \quad \beta_{1}+\beta_{2}=\beta
$$

where $e_{t}$ is the employment, and $k_{t}$ is the capital. We can rewrite the production function to a relation for average labour productivity in which $\beta$ is the returns to scale parameter. With some algebra

$$
y_{t}-e_{t}=(\beta-1) e_{t}+\beta_{2}\left(k_{t}-e_{t}-a_{t}\right)+\beta a_{t}
$$

where $\left(k_{t}-e_{t}-a_{t}\right)$ is the capital-labour ratio with labour measured in effective units. The technological process is assumed to follow a random walk:

$$
a_{t}=a_{t-1}+\varepsilon_{a, t}
$$

Let us to rewrite (1) as

$$
y_{t}-e_{t}=(\beta-1) e_{t}+\theta_{t}
$$

It is possible to derive two demand relations assuming cost-minimization and pricetaking firms:

$$
\begin{aligned}
& e_{t}=\beta^{-1} y_{t}-\left(w_{t}-p_{t}\right)+\varepsilon_{e, t} \\
& k_{t}=\beta^{-1} y_{t}-\left(i_{t}-p_{t}\right)+\varepsilon_{k, t}
\end{aligned}
$$

where $w_{t}$ is the wage rate, $i_{t}$ is the user cost of capital, and $p_{t}$ the price level. Combining the two relations, assumed to be stationary

$$
k_{t}-e_{t}-a_{t}=w_{t}-a_{t}-i_{t}+\varepsilon_{k, t}-\varepsilon_{e, t}
$$

Since we do not model $i_{t}$, we need to consider two cases, if the relation $\left(w_{t}-a_{t}-i_{t}\right)$ is a stationary process, from (A.2) and (A.5), defining $\theta_{t}$ in (1) as a productivity process, it is given by

$$
\theta_{t}=\beta a_{t}
$$

If $\left(w_{t}-a_{t}-i_{t}\right)$ is non-stationary $(\mathrm{I}(1))$, then we have

$$
\theta_{t}=\beta a_{t}+\beta_{2}\left(k_{t}-e_{t}-a_{t}\right)
$$

Since the interest of the analysis is on productivity, unemployment (employment) and vacancy, the inference of the model, leaving out $k_{t}$ and $i_{t}$, can be valid.

\section{A3 Cointegration and identification of the common trends model} (Tables A1, A2, A3)

Using dummies variables in the model can affect the distribution of the trace test, and so the approximation used for computing the critical values of the rank test in the I(1) 
Table A1 US test of stationarity

\begin{tabular}{lllllll}
\hline $\mathrm{r}$ & DGF & 5\% C.V. & LF_US & LY_E & UR_US & VR_US \\
\hline 1 & 3 & 7.815 & 6.098 & 11.679 & 26.131 & 25.986 \\
& \multirow{2}{*}{2} & \multirow{2}{*}{5.991} & 1.424 & 6.908 & 22.523 & 20.709 \\
2 & & {$[0.491]$} & {$[0.032]$} & {$[0.000]$} & {$[0.000]$} \\
& \multirow{2}{*}{1} & \multirow{2}{*}{3.841} & 0.243 & 5.132 & 5.311 & 2.186 \\
& & & {$[0.550]$} & {$[0.023]$} & {$[0.021]$} & {$[0.139]$} \\
\hline
\end{tabular}

LR-test, Chi-square $(4-r), P$-values in brackets

Table A2 IT test of stationarity

\begin{tabular}{lllllll}
\hline $\mathrm{r}$ & DGF & 5\% C.V. & LF & LY_E & UR_IT & VR_IT \\
\hline 1 & 4 & 7.815 & 13.088 & 6.035 & 16.745 & 9.201 \\
& & & {$[0.004]$} & {$[0.110]$} & {$[0.001]$} & {$[0.027]$} \\
2 & \multirow{2}{*}{3} & 5.991 & 10.619 & 1.818 & 12.396 & 9.113 \\
& \multirow{2}{*}{2} & & {$[0.005]$} & {$[0.403]$} & {$[0.002]$} & {$[0.011]$} \\
3 & \multirow{2}{*}{2.841} & 2.430 & 1.762 & 4.568 & 3.340 \\
& & & {$[0.119]$} & {$[0.184]$} & {$[0.033]$} & {$[0.068]$} \\
\hline
\end{tabular}

LR-test, Chi-square $(4-r), P$-values in brackets

Table A3 The US cointegration rank test

\begin{tabular}{lllllllll}
\hline $\mathrm{H}_{0}:$ Rank $=r$ & $p-r$ & $\hat{\lambda}_{i}$ & $\mathrm{i}$ & $\lambda_{T R A C E}$ & $\lambda_{T R A C E_{B C}}^{*}$ & $95 \%$ Crit. values & $P$-value & $P$-value* \\
\hline$r=0$ & 4 & 0.157 & 1 & 64.47 & 50.63 & 47.71 & 0.000 & 0.025 \\
$r \leq 1$ & 3 & 0.131 & 2 & 33.09 & 20.28 & 29.81 & 0.019 & 0.415 \\
$r \leq 2$ & 2 & 0.038 & 3 & 7.204 & 4.850 & 15.41 & 0.560 & 0.822 \\
$r \leq 3$ & 1 & 0.001 & 4 & 0.094 & 0.061 & 3.841 & 0.759 & 0.804 \\
\hline
\end{tabular}

Critical values are derived in Doornik (1998) and tabulated in Doornik (2003, Table 3), and Dennis et al. (2006, Table C.3), $\lambda_{T R A C E_{B C}}^{*}$, the Bartlett correction factors of the rank test statistic are derived in Johansen (2002)

models could be not valid. For such non-standard models, a simulation of the asymptotic critical values has been carried out both for the US and IT models. Comparing the simulated critical values to the standard ones, we note that their difference do not lead us to reconsider the choice of cointegration rank for both models (for IT model see below, Table A7). (Table A4).

Recursive estimation tests are based on the procedure to choose a baseline sample from the first part of the sample, and then estimate a first model and recursively test whether the last part of the sample has followed the same model. Therefore, in this way, various recursive tests are calculated starting from a baseline model estimated for a subsample $1, \ldots, T_{1}$, with $T_{1}<T$, and then the estimation is extended to the end point of the recursive sample, $t_{1}$, until the full sample is covered, where 
Table A4 US simulated critical values

Simulation of the asymptotic trace test distribution

Deterministic specification: unrestricted constant (DRIFT)

Number of replications (N): 2500

Length of random walks (T): 400

\begin{tabular}{|c|c|c|c|c|c|c|c|c|c|}
\hline \multicolumn{10}{|c|}{ Quantiles of the simulated rank test distribution } \\
\hline$p-r$ & $\mathrm{r}$ & Mean & S.E. & $50 \%$ & $75 \%$ & $80 \%$ & $85 \%$ & $90 \%$ & $95 \%$ \\
\hline 4 & 0 & 23.45 & 6.337 & 22.90 & 27.24 & 28.43 & 30.15 & 31.86 & 35.08 \\
\hline 3 & 1 & 11.99 & 4.649 & 11.43 & 14.81 & 15.69 & 16.61 & 17.97 & 20.66 \\
\hline 2 & 2 & 3.974 & 2.968 & 3.365 & 5.404 & 6.094 & 6.97 & 8.087 & 9.74 \\
\hline 1 & 3 & 0.000 & 0.000 & 0.000 & 0.000 & 0.000 & 0.00 & 0.000 & 0.00 \\
\hline \multicolumn{10}{|c|}{ I(1)-Analysis } \\
\hline$\overline{p-r}$ & $\mathrm{r}$ & \multicolumn{2}{|c|}{ Eig. value } & Trace & Trace* & Frac95 & $P$-value & \multicolumn{2}{|l|}{$P$-value* } \\
\hline 4 & 0 & 0.157 & \multicolumn{2}{|c|}{64.47} & 50.632 & 35.07 & 0.000 & \multicolumn{2}{|l|}{0.000} \\
\hline 3 & 1 & 0.131 & \multicolumn{2}{|c|}{33.09} & 20.283 & 20.66 & 0.001 & \multicolumn{2}{|l|}{0.054} \\
\hline 2 & 2 & 0.038 & \multicolumn{2}{|c|}{7.204} & 4.850 & 9.739 & 0.131 & \multicolumn{2}{|l|}{0.300} \\
\hline 1 & 3 & 0.001 & \multicolumn{2}{|c|}{0.094} & 0.061 & 0.000 & NA & \multicolumn{2}{|l|}{ NA } \\
\hline
\end{tabular}

$t_{1}=T_{1}, T_{1}+1, \ldots, T$. If we consider the ECM model (7), using the shorthand notation, then we have

$$
\begin{gathered}
Z_{0 t}=\Delta x_{t} \\
Z_{1 t}=x_{t-1} \\
Z_{2 t}=\left[\Delta x_{t-1}^{\prime}, \Delta x_{t-2}^{\prime}, \ldots, \Delta x_{t-p+1}^{\prime}, D_{t}\right]
\end{gathered}
$$

and writing (7) in the compact form

$$
Z_{0 t}=\alpha \beta^{\prime} Z_{1 t}+\Psi Z_{2 t}+\varepsilon_{t}
$$

we concentrate out the short-run effects $\Psi Z_{2 t}$ to obtain a 'cleaner' long-run adjustment model. hence, we can define the concentrated or $\boldsymbol{R}$-form model as

$$
R_{0 t}=\alpha \beta^{\prime} R_{1 t}+\tilde{\varepsilon}_{t}
$$

where $R_{0 t}$ and $R_{1 t}$ are residuals of OLS estimates of $Z_{0 t}$ and $Z_{1 t}$ on $Z_{2 t}$, respectively. $\boldsymbol{R}$-form model (A.8) is of interest to understand both the statistical and economic properties of the VECM model, so that the original VAR has been transformed into the 'clean' equilibrium adjustment form (A.8), which $M L$ estimator is derived in two steps. On the other hand the $\boldsymbol{X}$-form tests are based on the same procedure by reestimating all the parameters of the model (7). 

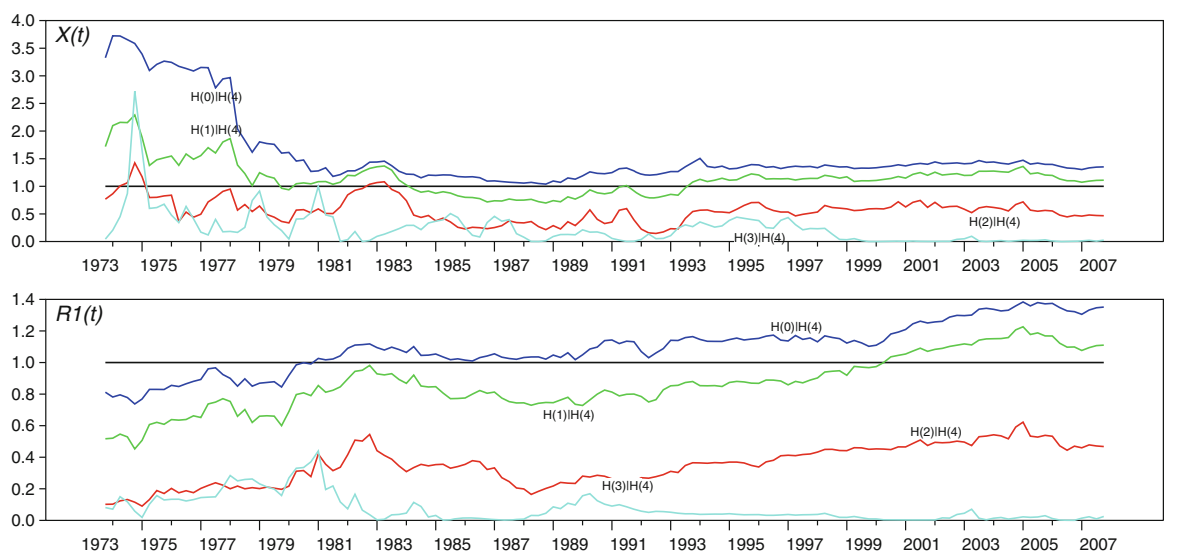

Fig. 16 The US recursive trace test

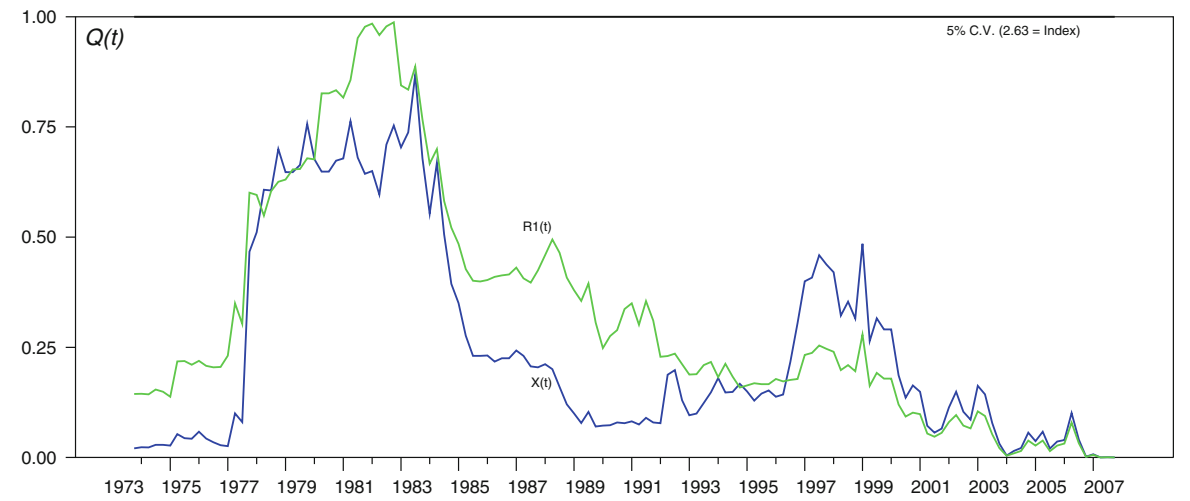

Fig. 17 The US max test of $\boldsymbol{\beta}$-constancy

The recursive trace test is based on the Johansen test for the cointegration rank:

$$
-2 \ln Q_{T}(H(r) \mid H(n))=-T \sum_{i=r+1}^{n} \ln \left(1-\hat{\lambda}_{i}\right), \text { for } r=1, \ldots, n-1
$$

The likelihood ratio test statistic for $H(r)$ in $H(n)$, either for the $\boldsymbol{X}$-form and $\boldsymbol{R}$ form models. The recursive graphs of the trace test divided by the $95 \%$ quantile of the asymptotic distribution

$$
\tau(j)=\left\{-t_{1} \sum_{i=1}^{j} \ln \left(1-\hat{\lambda}_{i}\right)\right\} / C_{.95}^{*}(j), \quad j=1, \ldots, n, t_{1}=T_{1}, \ldots, T
$$

where $\hat{\lambda}_{i}$ are the eigenvalues related to the estimated $\alpha_{i}$ and $\beta_{i}$, which provide a visual impression about the constancy of the cointegration relations. Since $\lambda_{i}$ tends 


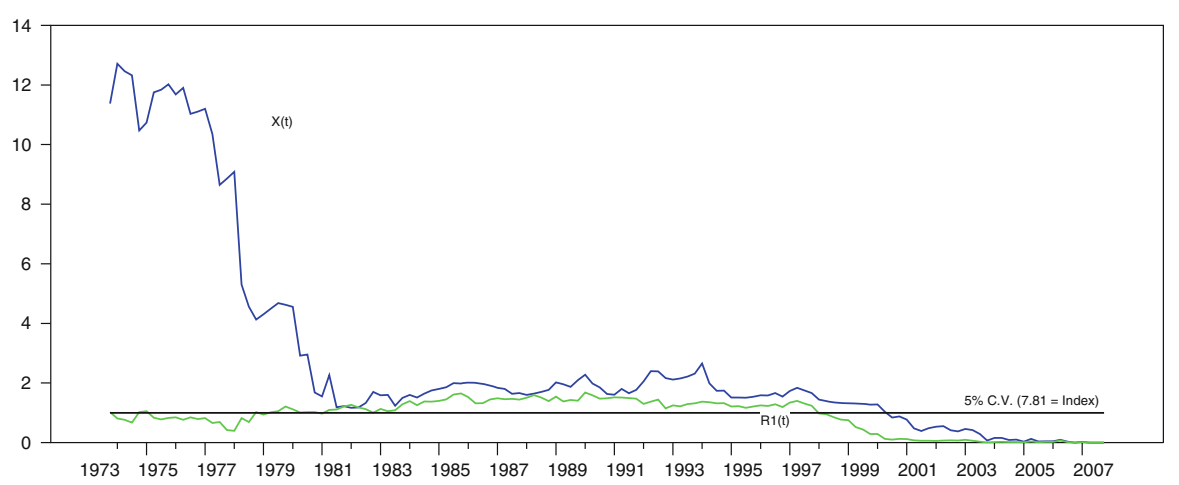

Fig. 18 The US test of 'Known Beta' $\beta_{0} \in \operatorname{sp} \beta^{\left(t_{1}\right)}$

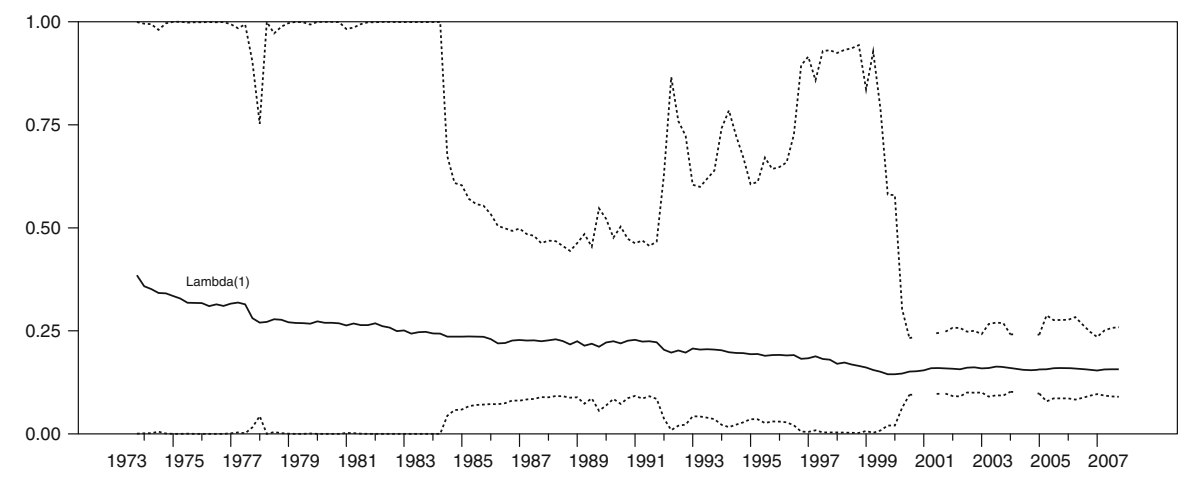

Fig. 19 Eigenvalue time path

to a constant for $i \leq r$ and to zero for $i>r, \tau(j)$ should be upward sloping for $j \leq r$ and constant for $j>r$, so that in Fig. 16 are plotted the $r$ 's time paths of $\hat{\lambda}_{i}$ (for $i=1, \ldots, r$ ), evaluated in each step of the recursion (for each value of $t_{1}$ ). The number of test statistics greater than unity corresponds to the number of cointegration relations at the $5 \%$ significance level, i.e. values greater than unity imply rejection of the null hypothesis at a 5\% significance level. Hence, the graphs give some support to our choice of three unit roots (i.e. $r=1$ ).

The max test focuses on testing changes in the beta vectors, and tests the hypothesis:

$$
H_{\beta}: \hat{\beta}_{t_{1}}=\beta_{T} \quad \text { for } t_{1}=T_{1}, \ldots, T
$$

It is a $L M$ type test for parameter constancy in regression models deriving by Nyblom (1989), and extended to analyse models with I(1) processes. In Fig. 17, the test statistics have been scaled by the asymptotic 5\% critical value under the null of constant parameters. The test is rather conservative, implying that there is strong evidence for non-constancy of beta (a signal of large deviations from the null) when the test rejects (the test statistics are above unity line). 


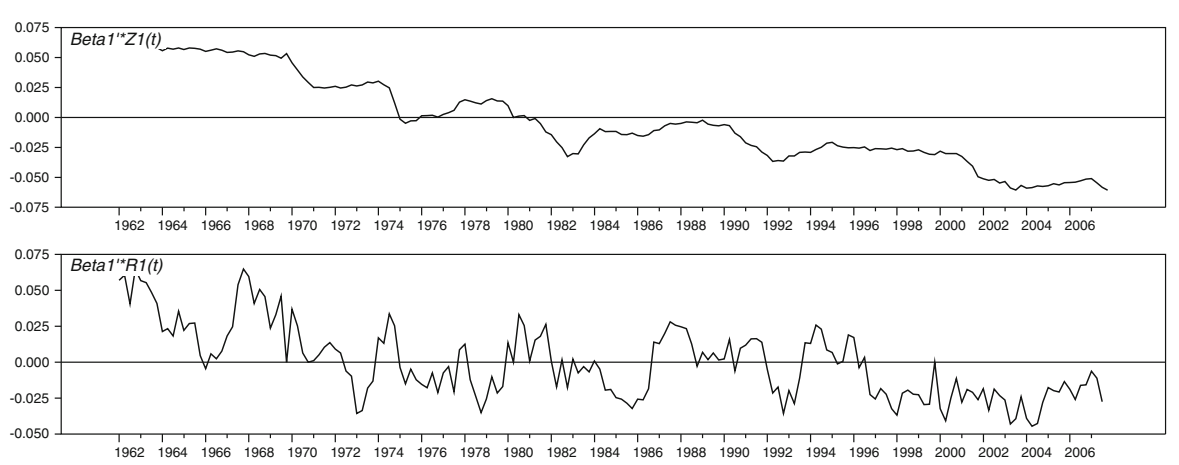

Fig. 20 US cointegration relationship
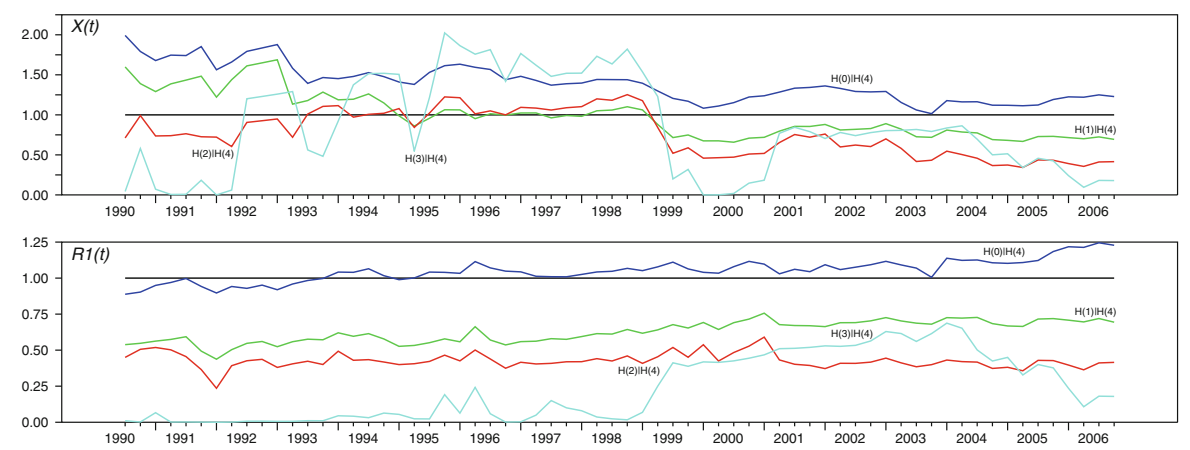

Fig. 21 IT recursive trace test

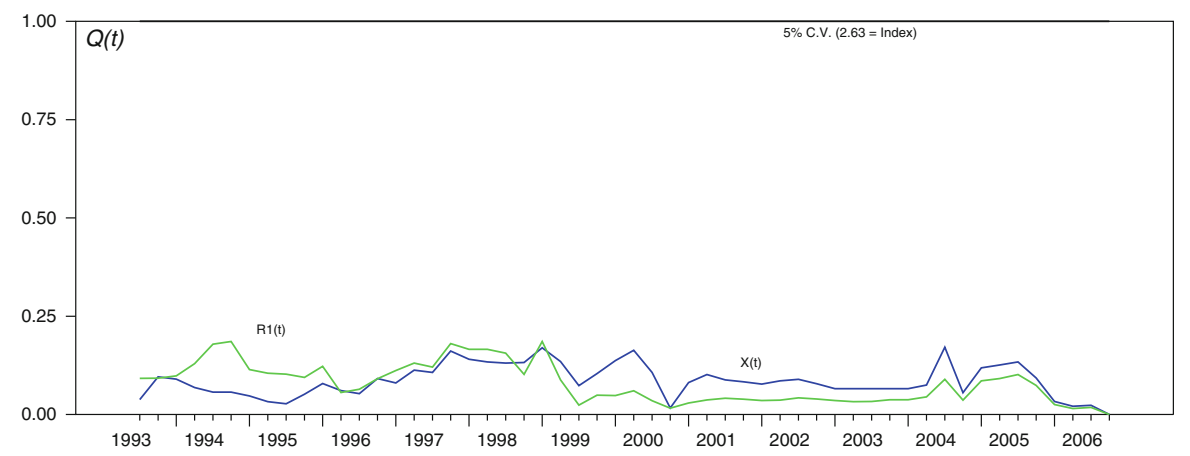

Fig. 22 IT max test of $\boldsymbol{\beta}$-constancy

The test of 'Known Beta' is based on the null hypothesis that the beta relation(s) are constant over a reference period that can be the full sample or any subsample of it. Figure 18 is obtained by recursively adding more observations to $T_{1}$, thus considering the recursive test of the hypothesis

$$
H_{\beta}: \beta_{0} \in \operatorname{sp} \beta^{\left(t_{1}\right)}, \quad t_{1}=T_{1}, \ldots, T
$$




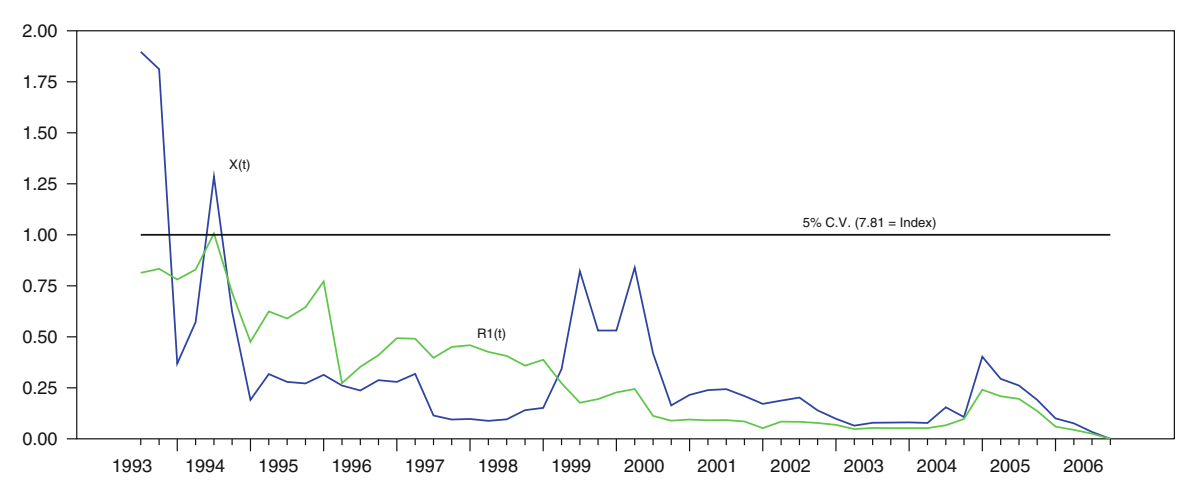

Fig. 23 IT test of 'Known Beta' $\beta_{0} \in s p \beta^{\left(t_{1}\right)}$

Table A5 Estimates of the theoretical parameters for the US and Italy

\begin{tabular}{lcc}
\hline Parameter & US & Italy \\
\hline$\gamma$ & 1.78 & 1.16 \\
$\eta$ & -2.42 & -1.34 \\
$\beta$ & 1.16 & 1.03 \\
$\sigma_{s}$ & 0.00621 & 0.0044 \\
$\sigma_{y}$ & 0.00373 & 0.0017 \\
$\sigma_{c}$ & 0.01425 & 0.0046 \\
\hline
\end{tabular}

Table A6 IT cointegration rank test

\begin{tabular}{lllllllll}
\hline $\mathrm{H}_{0}:$ Rank $=r$ & $p-r$ & $\hat{\lambda}_{i}$ & $\mathrm{I}$ & $\lambda_{T R A C E}$ & $\lambda_{T R A C E_{B C}}^{*}$ & $95 \%$ crit. values & $P$-value & $P$-value* \\
\hline$r=0$ & 4 & 0.511 & 1 & 69.14 & 51.46 & 47.71 & 0.000 & 0.020 \\
$r \leq 1$ & 3 & 0.254 & 2 & 30.53 & 22.00 & 29.80 & 0.041 & 0.308 \\
$r \leq 2$ & 2 & 0.165 & 3 & 14.71 & 10.62 & 15.41 & 0.064 & 0.240 \\
$r \leq 3$ & 1 & 0.088 & 4 & 4.988 & 4.081 & 3.841 & 0.026 & 0.043 \\
\hline
\end{tabular}

Critical values are derived in Doornik (1998) and tabulated in Doornik (2003, Table 3), and Dennis et al. (2006, Table C.3), $\lambda_{T R A C E_{B C}}^{*}$, the Bartlett correction factors of the rank test statistic are derived in Johansen (2002)

where $\hat{\beta}_{0}$ is considered a known matrix. The test statistic is given by

$$
-2 \ln Q\left(H_{\beta} \mid \beta^{\left(t_{1}\right)}\right)=t_{1} \sum_{i=1}^{r} \ln \frac{1-\hat{\rho}_{i}^{\left(t_{1}\right)}}{1-\hat{\lambda}_{i}^{\left(t_{1}\right)}}
$$

where $\hat{\rho}_{i}^{\left(t_{1}\right)}$ is the solution of the restricted eigenvalue problem, and $\hat{\lambda}_{i}^{\left(t_{1}\right)}$ is the solution of the unrestricted eigenvalue problem. The test is asymptotically distributed as $\chi^{2}$ with $r(n 1-r)$ d.o.f. The $\boldsymbol{X}$-form model re-estimates all the parameters, therefore the degrees of freedom are fewer than for the $\boldsymbol{R}$-form, and so this can lead to $\boldsymbol{X}$-form graphs with increased volatility at the beginning of the recursive sample. Moreover, each kind of test analyses the model by different views, so that one test might show non-constant characteristics not depicted by other tests. 
Table A7 IT simulated critical values

Simulation of the asymptotic trace test distribution

Deterministic specification: Unrestricted Constant (DRIFT)

Number of replications (N): 2500

Length of random walks (T): 400

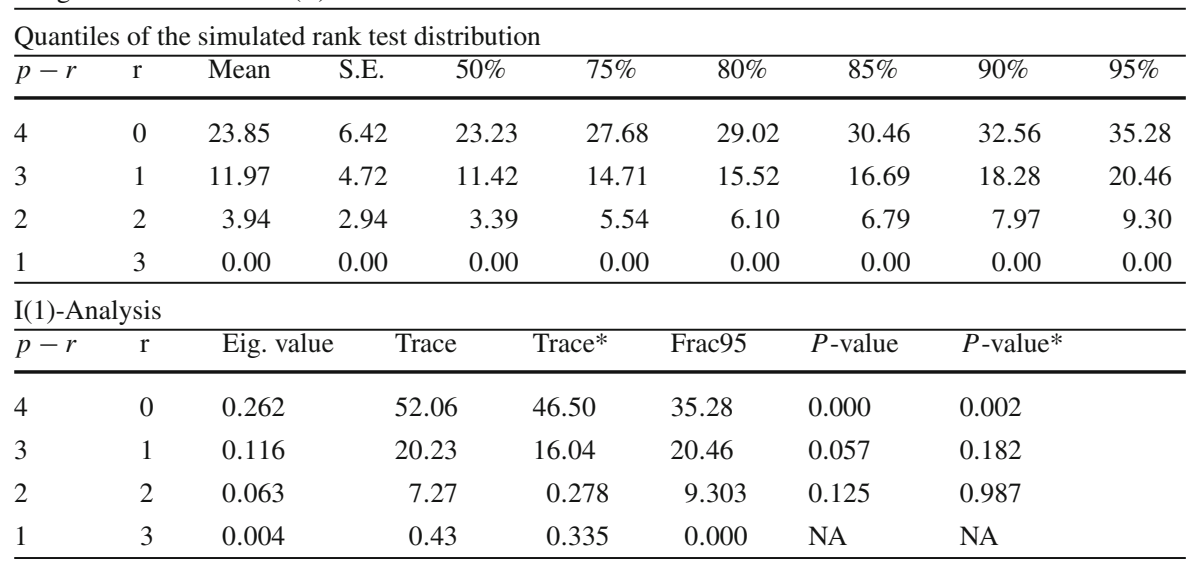

Table A8 FEVD of IT unemployment

\begin{tabular}{lllll}
\hline Quarter & $\psi$ & $\theta$ & $\omega$ & $\varepsilon_{m}$ \\
\hline 1 & 0.020 & 0.022 & 0.080 & 0.878 \\
4 & 0.016 & 0.118 & 0.251 & 0.615 \\
8 & 0.026 & 0.230 & 0.308 & 0.435 \\
16 & 0.038 & 0.305 & 0.309 & 0.348 \\
24 & 0.033 & 0.346 & 0.314 & 0.307 \\
32 & 0.026 & 0.381 & 0.320 & 0.274 \\
$\infty$ & 0.214 & 0.542 & 0.244 & 0.000 \\
\hline
\end{tabular}

Table A9 FEVD of IT vacancies

\begin{tabular}{lllll}
\hline Quarter & $\psi$ & $\theta$ & $\omega$ & $\varepsilon_{m}$ \\
\hline 1 & 0.000 & 0.374 & 0.582 & 0.044 \\
4 & 0.006 & 0.580 & 0.386 & 0.028 \\
8 & 0.012 & 0.445 & 0.525 & 0.016 \\
16 & 0.030 & 0.298 & 0.663 & 0.009 \\
24 & 0.041 & 0.247 & 0.705 & 0.007 \\
32 & 0.047 & 0.221 & 0.727 & 0.005 \\
$\infty$ & 0.048 & 0.139 & 0.813 & 0.000 \\
\hline
\end{tabular}


Figure 19 shows the graph of time path of the recursively $r$ largest eigenvalue(s) of the model and its $95 \%$ confidence bands. The evaluation of the time path of $\hat{\lambda}_{i}(i=1, \ldots, r)$ can be seen as an evaluation of the $i$ 'th column of $\hat{\beta}$ (or $\hat{\alpha}$ ), and hence non-constancy of $\hat{\beta}$ or $\hat{\alpha}$ will be reflected in the estimated eigenvalue(s). The graph of $\hat{\lambda}_{1}$ shows that there are no large changes in all the samples, even though the confidence bands display some variability. (Figs. 20, 21, 22, 23; Tables A5, A6, A7, A8, A9).

The market tightness relation, in terms of the four left-hand side variables in (6), it can be written as

$$
-\gamma\left(y_{t}-e_{t}\right)-\left(l_{t}-e_{t}\right)+v_{t}=\varepsilon_{m, t}
$$

\section{References}

Abraham KG (1987) Help-wanted advertising, job vacancies, and unemployment. Brook Pap Econ Act $1: 207-248$

Bagliano FC, Morana C (2003) Measuring us core inflation: a common trends approach. J Macroecon 25(2):197-212

Barlevy G (2002) The sullying effect of recessions. Rev Econ Stud 69(1):65-96

Blanchard OJ, Diamond P (1989) The Beveridge curve. Brook Pap Econ Act 1:1-76

Bleakley H, Fuhrer JC (1997) Shifts in the Beveridge curve, job matching, and labour market dynamics. New Engl Econ Rev 97:3-19

Bragato S (1990) La curva di Beveridge e le componenti della disoccupazione in Italia (1980-88). Econ Lavoro 24(4):111-122

Braun H, De Bock R, Di Cecio R (2009) Aggregate shocks and labor market fluctuations. Fed Res Bank St Louis Rev 91(3):155-178

Carlin W, Soskice D (1990) Macroeconomics and the Wage Bargain. A modern approach to employment, inflation and the exchange rate. Oxford University Press, Oxford

De Stefanis S, Fonseca R (2007) Matching efficiency and labour market reform in Italy: a macroeconometric assessment. Labour 21(1):57-84

Dennis JG, Hansen H, Johansen S, Juselius K (2006) CATS in RATS: cointegration analysis of time series, Version 2. Estima, Evanston, Illinois, USA

Doornik JA (1998) Approximations to the asymptotic distributions of cointegration tests. J Econ Surv 12(5):573-593

Doornik JA (2003) Asymptotic tables for cointegration tests based on the gamma-distribution approximation. Nuffield College, University of Oxford, Oxford

Flinn JT (2002) Labour market structure inequality: a comparison of italy and the U.S. Rev Econ Stud 69(3):611-645

Fujita S, Ramey G (2007) Job matching and propagation. J Econ Dynam Control 31(11):3671-3698

Giannini M (2006) Job search mechanism and individual behaviour. Comp Econ 27(1):89-113

Hahn F, Solow R (1995) A critical essay on modern macroeconomic theory. MIT Press, Cambridge

Hall R (1991) Labor demand, labor supply and employment volatility. NBER macroecon annual. Cambridge, MIT Press

Hall R (2000) Reorganization. Carnegie-Rochester conf series on public policy

Hansen H, Johansen S (1999) Some tests for parameter constancy in the cointegrated VAR. Econ J 2(2): 306-333

Hansen H, Warne A (2001) The cause of Danish unemployment: demand or supply shocks?. Emp Econ 26(3):461-486

Jackman R, Layard R, Nickell S (2005) Unemployment: macroeconomic performance and the labour market, 2nd edn. Oxford University Press, Oxford

Jacobson T, Vredin A, Warne A (1997) Common trends and hysteresis in Scandinavian unemployment. Europ Econ Rev 41:1781-1816

Johansen S (2000) A bartlett correction factor for tests on cointegrating relations. Econ Theory 16:740-778 
Johansen S (2002) A small sample correction of the test for cointegration rank in the vector autoregressive model. Econometrica 70(5):1929-1961

Johansen S, Nielsen BG (1993) Asymptotics for cointegration rank tests in the presence of intervention dummies. Manual for the simulation program Disco. WP University of Copenhagen

Juselius K (2006) The cointegrated VAR Model: methodology and applications. Advanced texts in econometrics. Oxford University Press, Oxford

Katz LF, Krueger A (1999) The high-pressure U.S. labor market of the 1990s. Brook Pap Econ Act 1:1-65

King RG, Plosser CI, Stock JH, Watson MW (1991) Stochastic trends and economic fluctuations. AER $81: 819-840$

McDonald IM (1990) Inflation and unemployment macroeconomics with a range of equilibria. Basil Blackwell Ltd, Oxford

McDonald IM, Sibly H (2001) How monetary policy can have permanent real effects with only temporary nominal rigidity. Scott J Polit Econ 48(5):532-546

Mocavini A, Paliotta A (2000) Job vacancies in Italia. Il quadro teorico, le indagini, le evidenze empiriche. ISFOL, Monografie sul Mercato del Lavoro e le Politiche per l'impiego, n. 6/2000

Mortensen DT, Pissarides CA (1994) Job creation and job destruction in the theory of unemployment. Rev Econ Stud 61(3):397-415

Mortensen DT, Pissarides CA (1999) Job reallocation, employment fluctuations and unemployment. In: Taylor JB, Woodford M (eds) Handbook of macroeconomics, vol 1. North-Holland, Amsterdam

Nyblom J (1989) Testing for the constancy of parameters over time. J Am Stat Assoc 84:223-230

Pissarides CA (2000) Equilibrium unemployment, 2nd edn. MIT Press, Cambridge, MA

Schindler M (2009) The Italian labor market: recent trends, institutions and reform options. IMF, WP 09/47

Shimer R (2005) The cyclical behaviour of equilibrium unemployment and vacancies. AER 95(1):25-49

Shimer R (2007) Mismatch. AER 97(4):1074-1101

Stock JH, Watson MW (1988) Testing for common trends. J Am Stat Assoc 83(404):1097-1107

Valletta RG (2005) Why Has U.S. Beveridge curve shifted back? New evidence using regional data. WP 2005-25, Fed Res Bank of San Francisco

Warne A (1993) A common trends model: identification, estimation and inference. Semin Pap n. 555, Inst for Int Econ Stud, Stockholm University 